\title{
Ocean Seismic Network Pilot Experiment
}

\section{R. A. Stephen}

Department of Geology and Geophysics, Woods Hole Oceanographic Institution (MS24), 360 Woods Hole Road, Woods Hole, Massachusetts 02543, USA (rstephen@whoi.edu)

\section{F. N. Spiess}

Marine Physical Laboratory, Scripps Institution of Oceanography, 9500 Gilman Drive La Jolla, California 92093, USA (fspiess@ucsd.edu)

\section{J. A. Collins}

Department of Geology and Geophysics, Woods Hole Oceanographic Institution (MS24), 360 Woods Hole Road, Woods Hole, Massachusetts 02543, USA (jcollins@whoi.edu)

\section{J. A. Hildebrand}

Marine Physical Laboratory, Scripps Institution of Oceanography, 9500 Gilman Drive La Jolla, California 92093, USA (jhildebrand@ucsd.edu)

\section{J. A. Orcutt}

Cecil H. and Ida M. Green Institute of Geophysics and Planetary Physics, Scripps Institution of Oceanography, 8765 Biological Grade, EAMS Code 6317, La Jolla, California 92037, USA

Now at Director's Office (0210), Scripps Institution of Oceanography, 8620 Discovery Way, La Jolla, California 92037, USA(jorcutt@igpp.ucsd.edu)

\section{K. R. Peal}

Department of Applied Ocean Physics and Engineering, Woods Hole Oceanographic Institution (MS10), 98 Water Street, Woods Hole, Massachusetts 02543, USA (kpeal@whoi.edu)

\section{F. L. Vernon}

Cecil H. and Ida M. Green Institute of Geophysics and Planetary Physics, Scripps Institution of Oceanography, 8765 Biological Grade, EAMS Code 6317, La Jolla, California 92037, USA (flvernon@ucsd.edu)

\section{F. B. Wooding}

Department of Applied Ocean Physics and Engineering, Woods Hole Oceanographic Institution (MS10), 98 Water Street, Woods Hole, Massachusetts 02543, USA (bwooding@whoi.edu)

[1] The primary goal of the Ocean Seismic Network Pilot Experiment (OSNPE) was to learn how to make high quality broadband seismic measurements on the ocean bottom in preparation for a permanent ocean seismic network. The experiment also had implications for the development of a capability for temporary (e.g., 1 year duration) seismic experiments on the ocean floor. Equipment for installing, operating and monitoring borehole observatories in the deep sea was also tested including a lead-in package, a logging probe, a wire line packer and a control vehicle. The control vehicle was used in three modes during the experiment: for observation of seafloor features and equipment, for equipment launch and recovery, and for power supply and telemetry between ocean bottom units and the ship. The OSNPE which was completed in June 1998 acquired almost four months of continuous data and it demonstrated clearly that a combination of shallow buried and borehole broadband sensors could provide comparable quality data to broadband seismic installations on islands and continents. Burial in soft mud appears to be adequate at 
frequencies below the microseism peak. Although the borehole sensor was subject to installation noise at low frequencies ( 0.6 to $50 \mathrm{mHz}$ ), analysis of the OSNPE data provides new insights into our understanding of ocean bottom ambient noise. The OSNPE results clearly demonstrate the importance of sediment borne shear modes in ocean bottom ambient noise behavior. Ambient noise drops significantly at high frequencies for a sensor placed just at the sediment basalt interface. At frequencies above the microseism peak, there are two reasons that ocean bottom stations have been generally regarded as noisier than island or land stations: ocean bottom stations are closer to the noise source (the surface gravity waves) and most ocean bottom stations to date have been installed on low rigidity sediments where they are subject to the effects of shear wave resonances. When sensors are placed in boreholes in basement the performance of ocean bottom seismic stations approaches that of continental and island stations. A broadband borehole seismic station should be included in any real-time ocean bottom observatory.

Components: 19,024 words, 30 figures.

Keywords: Broadband seismology; ocean seismic network; ambient noise; earthquakes; marine seismology; Ocean Drilling Project Leg 136.

Index Terms: 7294 Seismology: Instruments and techniques; 7203 Seismology: Body wave propagation; 7255 Seismology: Surface waves and free oscillations.

Received 30 November 2002; Revised 1 August 2003; Accepted 19 August 2003; Published 31 October 2003.

Stephen, R. A., F. N. Spiess, J. A. Collins, J. A. Hildebrand, J. A. Orcutt, K. R. Peal, F. L. Vernon, and F. B. Wooding, Ocean Seismic Network Pilot Experiment, Geochem. Geophys. Geosyst., 4(10), 1092, doi:10.1029/2002GC000485, 2003.

\section{Introduction}

[2] By extending the land based broadband networks to the ocean bottom, large portions of Earth that have been previously unobservable, will be seismically illuminated. A major milestone in the development of this technology was accomplished in the winter and spring of 1998, on the Ocean Seismic Network Pilot Experiment (OSNPE) southwest of Oahu. Three designs of ocean bottom broadband seismometer (a seafloor instrument, a shallow-buried instrument, and a borehole instrument) acquired data simultaneously for over three months. Over two hundred and thirty earthquake events were detected and ambient noise was observed over a range of sea-states, wind conditions, and bottom currents. The performance of these sensors can be compared with broadband sensors on the Hawaiian Islands and with other island and continental seismic stations around the Pacific.

[3] The goal of the Ocean Seismic Network Pilot Experiment was to learn how to make high quality broadband (about $0.001-100 \mathrm{~Hz}$ ) seismic measure- ments on the seafloor in preparation for extending the GSN (Global Seismographic Network) and PASSCAL (Program for Array Seismic Studies of the Continental Lithosphere) style experiments to the ocean basins [Forsyth et al., 1991; Kasahara et al., 1998; Montagner and Lancelot, 1995; Purdy and Dziewonski, 1988; Purdy and Orcutt, 1995]. The Incorporated Research Institutions for Seismology (IRIS) GSN global site plan, in conjunction with the international Federation of Digital Seismographic Networks (FDSN), calls for 128 stations, uniformly distributed around the globe, to address a broad spectrum of problems in whole Earth seismology [Butler, 1995; IRIS, 1995]. Since over two-thirds of Earth's surface is covered by water, "uniform coverage" implies that more than 20 stations need to be located on the deep ocean floor, far from continents or islands (Figure 1).

[4] Preliminary results from the OSNPE have been published by Collins et al. [2002, 2001] and F. H. Sutherland, F. L. Vernon, J. A. Orcutt, J. A. Collins, and R. A. Stephen, Results from OSNPE: Low threshold magnitudes for ocean-bottom 


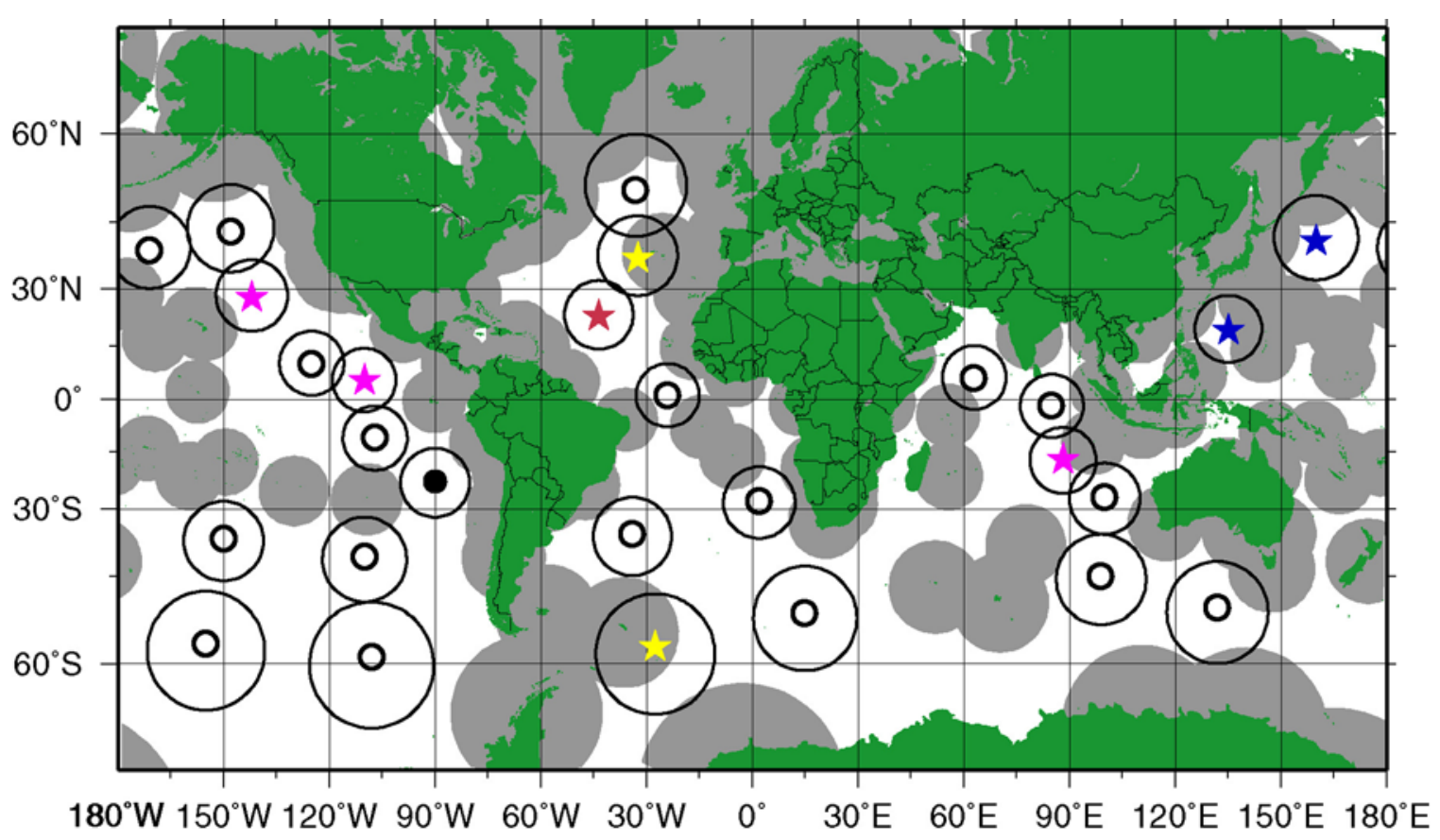

Figure 1. This figure summarizes the role of ocean borehole sites in global seismic coverage. The grey shaded regions indicate the surface coverage out to $1000 \mathrm{~km}$ from continent and island stations. (These are distorted in the projection.) White spaces are gaps in the land based coverage. Existing and proposed ocean stations for global coverage are indicated by symbols surrounded by black circles at approximately $1000 \mathrm{~km}$ radius. The different symbols show different levels of progress at the ocean sites: red star, the Mid-Atlantic Ridge test site (the OSNPE and Japan Sea regional test sites are not shown); blue stars, presently operating borehole observatories (the Japan Trench regional sites are not shown); maroon stars, sites at which boreholes have been drilled but have not yet been instrumented; solid and open black circles, high priority ION sites proposed in 1996 but not yet drilled; yellow stars, other proposed sites which have not yet been drilled. [Butler, 1995; Purdy and Dziewonski, 1988]

recording (manuscript submitted to Bulletin of the Seismological Society of America, 2003, hereinafter referred to as Sutherland et al., submitted manuscript, 2003) and a report on the burial system for broadband ocean bottom seismometers has been published by Wooding et al. [2001]. The objective of this paper is to provide some background material on work that lead to the OSNPE, to describe the OSNPE equipment and operations in more detail, to present some results of ambient noise, and to explain how our knowledge of ocean bottom seismology has changed as a result of the OSNPE.

\section{Background}

[5] The first ULF (Ultra-Low Frequency, 0.001$1 \mathrm{~Hz}$ ) ambient seismic noise measurements were made in the 1960's using the Columbia-Point Arena ocean-bottom seismic station [Sutton and
Barstow, 1990; Sutton et al., 1965]. Interest in ULF acoustics was spurred in the mid-1980s by the development of the differential pressure gauge [Cox et al., 1984; Webb and Cox, 1986]. Also in the mid-1980s the development of high dynamic range, broadband seismometers revolutionized whole earth seismometry [Jordan et al., 1987; Steim, 1986; Usher et al., 1978; Wielandt, 1983; Wielandt and Streckeisen, 1982; Lay and Wallace, 1995, Figure 5.13]. A number of organizations were formed to acquire and disseminate high quality seismic data to uniform specifications and in a uniform format (e.g., IRIS). The Global Seismic Network set as its goal the uniform distribution of 128 seismic stations over the surface of the globe, to provide high quality data sets for whole Earth tomography [e.g., Woodhouse and Dziewonski, 1989] and other Earth scale problems [Wysession, 1996]. It became clear that to accomplish this goal would require 
about twenty permanent stations on the deep ocean floor [Purdy and Dziewonski, 1988]. Numerous national and international committees, programs and workshops were established to develop the technology necessary for permanent ocean bottom observatories [Carson et al., 1996; Forsyth et al., 1991; Montagner and Lancelot, 1995; Purdy and Orcutt, 1995].

[6] Although broadband seismic and pressure measurements had been made on the seafloor [Auld et al., 1969; Barstow et al., 1989; Dozorov and Soloviev, 1992; Latham and Sutton, 1966; Sutton and Barstow, 1990; Webb and Schultz, 1992; Webb, 1988; Webb et al., 1994], the issue of what could be gained by placing a sensor below the seafloor was unresolved prior to the OSNPE. It is convenient in our discussion to define "broadband" as frequencies between $0.001 \mathrm{~Hz}$ and $100 \mathrm{~Hz}$; ULF (Ultra Low Frequency) as the band from 0.001 to $1 \mathrm{~Hz}$; and VLF (Very Low Frequency) as the band from 1 to $100 \mathrm{~Hz}$. The largest ambient noise levels at the ocean bottom in acceleration units (between 0.001 and $100 \mathrm{~Hz}$ ) generally occur at the microseism peak which is usually near 0.16 to $0.3 \mathrm{~Hz}$. In the passive, earthquake seismology community, the terms "long period" (or "low frequency") and "short period" (or "high frequency") identify the bands below and above the microseism peak (displayed in frequency), respectively. It is challenging to develop a seismic sensor which will span the full band from $0.001 \mathrm{~Hz}$ to $100 \mathrm{~Hz}$. Practical installations generally require two systems: a modern active feedback seismometer for the ULF range and a passive more traditional sensor for the VLF range. In both cases the proper installation of seismometers on or below the seafloor was an outstanding issue that needed to be resolved prior to committing to an extensive permanent network.

[7] Observations and models of ambient noise near the seafloor indicated a preponderance of interface waves, perhaps generated by scattering from seafloor heterogeneities [Bradley, 1994; Bradner et al., 1965; Dougherty and Stephen, 1988; Duennebier et al., 1987a; Latham and Nowroozi, 1968; Latham and Sutton, 1966; Orcutt et al., 1993a; Orcutt et al., 1993b; Schreiner and
Dorman, 1990; Webb, 1992]. Also large eddies in the ocean near the seafloor induce pressure fluctuations which tilt the seafloor and generate a seismic signal at frequencies below a few Hertz [Webb, 1988]. The very low shear modulus of most sea-bottom sediments also cause them to act as mechanical amplifiers for shear wave amplitudes, so that the ratio of compressional to shear displacements can be dramatically different on the seafloor than in competent rock either on land or in ocean bottom boreholes. This mechanical amplification will affect both signals and noise and can contribute to anomalous behavior even at very low frequencies where the wavelengths are much longer than the sediments are thick. Even aside from these mechanisms that affect real noise at the ocean bottom, obtaining faithful ground motion records with a sensor directly on a fluid-solid boundary can be a challenging task [Barash et al., 1994; Duennebier and Sutton, 1995; Sutton and Duennebier, 1988; Sutton et al., 1981; Trehu and Sutton, 1994] and deep sea currents flowing against the seismograph cause instrument noise [Duennebier et al., 1981]. There was ample justification for considering shallow buried and deep borehole sensors for ocean bottom seismometry.

[8] In shallow water studies, experiments had shown that burying the seismometer reduced ambient noise levels [Duennebier et al., 1991; Sutton and Duennebier, 1988; Trevorrow et al., 1989a; Trevorrow et al., 1989b]. In deep water, a number of studies had also observed that ambient noise at frequencies above the microseism peak was consistently quieter for both vertical and horizontal sensors in boreholes than at the seafloor [Adair et al., 1984; Bradley, 1994; Bradley et al., 1997; Duennebier et al., 1987a; Hedlin and Orcutt, 1989; Stephen et al., 1994]. In one study where the VLF noise was not quieter in the borehole than on the seafloor, the sensor had been clamped at only $190 \mathrm{~m}$ depth into soft sediment [Carter et al., 1984]. Bradley et al. [1997] summarized results from a study in the Blake-Bahama basin with sediments over $1 \mathrm{~km}$ thick in about $5 \mathrm{~km}$ of water [Stephen et al., 1994]. At the microseism peak both vertical and horizontal components had uniform levels in the upper $100 \mathrm{~m}$. However, above the 
microseism peak at frequencies up to $15 \mathrm{~Hz}$, sensors at $70 \mathrm{~m}$ were generally quieter than at the seafloor by up to $15 \mathrm{~dB}$ for vertical sensors and by up to $20 \mathrm{~dB}$ for horizontal sensors. At about $5 \mathrm{~Hz}$ there seemed to be a resonance in the horizontal components at the seafloor that was attenuated by $40 \mathrm{~dB}$ at $100 \mathrm{~m}$ sub-bottom.

[9] There were considerably fewer observations of ambient noise below the seafloor at frequencies below the microseism peak. The first broadband seismic observation in a borehole in competent rock beneath the deep seafloor was carried out in the Japan Sea in the Fall of 1989 but reliable ambient noise data below $0.1 \mathrm{~Hz}$ was not obtained [Kanazawa et al., 1992; Suyehiro et al., 1992].

[10] Montagner et al. [1994a, 1994b], on a short term borehole experiment near the mid-Atlantic Ridge in the Spring of 1992, observed that below $1 \mathrm{~Hz}$ the ambient noise level on the seafloor is comparable to good continental stations. At frequencies below $0.05 \mathrm{~Hz}$ the borehole sensor was noisier than a seafloor sensor. However, during the course of the 10 day deployment, during which the sea was always calm, the borehole sensor became progressively quieter and the equilibrium stage for the sensors was not reached by the end of the experiment. In this deployment the sensor was not clamped, it sat on the bottom of the hole and nothing was done to prevent water from circulating around the sensor, a potential source of seismic noise. The sensor was not even sitting on hard basement because there was about $110 \mathrm{~m}$ of fill (the hole had been drilled to $406 \mathrm{~m}$ below seafloor (bsf) through $150 \mathrm{~m}$ of sediment but the seismometer was at $296 \mathrm{mbsf}$ ). Also borehole temperature measurements made earlier in the hole indicated that water was flowing in the hole [Legrand et al., 1989] which could have contributed installation noise to the borehole sensor directly or by vibration of the cable. The seafloor sensor on this experiment was deployed in a depression on the seafloor that may have been caused by earlier drilling activities and its performance may correspond to a combination of buried and seafloor styles.

[11] During the MOISE experiment in the summer of 1997, three months of continuous, three com- ponent broadband data was obtained in Monterey Bay (about $1000 \mathrm{~m}$ water depth) for a partially buried sensor in soft sediments [Romanowicz et al., 1998]. At frequencies above $1 \mathrm{~Hz}$ and in the noise notch from 0.033 to $0.1 \mathrm{~Hz}$ noise levels were comparable to near-by land stations and noise levels correlated with sea bottom currents. At the microseism peak noise levels were $20 \mathrm{~dB}$ louder than at nearby land stations. A collocated borehole is not yet available at the Monterey Bay site to test the response of sensors placed in basement.

[12] There are a number of issues that need to be considered in evaluating the benefits of borehole seismometers over seafloor or shallow buried seismometers in the seafloor [Stephen, 1995]. Measurements of ambient noise on and within the seafloor in the ULF and VLF bands prior to the OSN (Ocean Seismic Network) Pilot Experiment indicated that performance would depend on at least the following factors: (1) type of sensor: vertical versus horizontal components (or, in some cases, even hydrophones or differential pressure gauges), arrays of receivers, etc; (2) geologic factors such as sediment thickness, sediment rigidity, shear wave attenuation, water depth, etc. (Does the low rigidity sediment itself move faithfully with the "true" basement motion? Since gravity wave amplitudes decay with depth in the ocean, their ability to excite seismic noise by direct loading will be water depth dependent.); (3) proximity to land and beaches (Surface gravity wave interactions with shorelines have been shown to excite seismic wave noise in a number of bands [Bromirski, 2001; Bromirski and Duennebier, 2002].); (4) sea state and weather (see Babcock et $a l$. [1994] for examples of the dependence of ambient noise on weather conditions); (5) frequency band of interest and the nature of the signals of interest; (6) depth of the seismometer below the seafloor; (7) clamping of seismometers in basement or in sediments, or in or out of casing; (8) influence of bottom currents, either directly on the sensor or as a mechanism for generating actual noise in the seafloor; (9) in the case of borehole sensors, the clamping mechanism, seismometer design (weight, length, etc), the presence or absence of fluid flow in the borehole and formation, the effects of cables, reentry cones, and even the borehole itself on the 


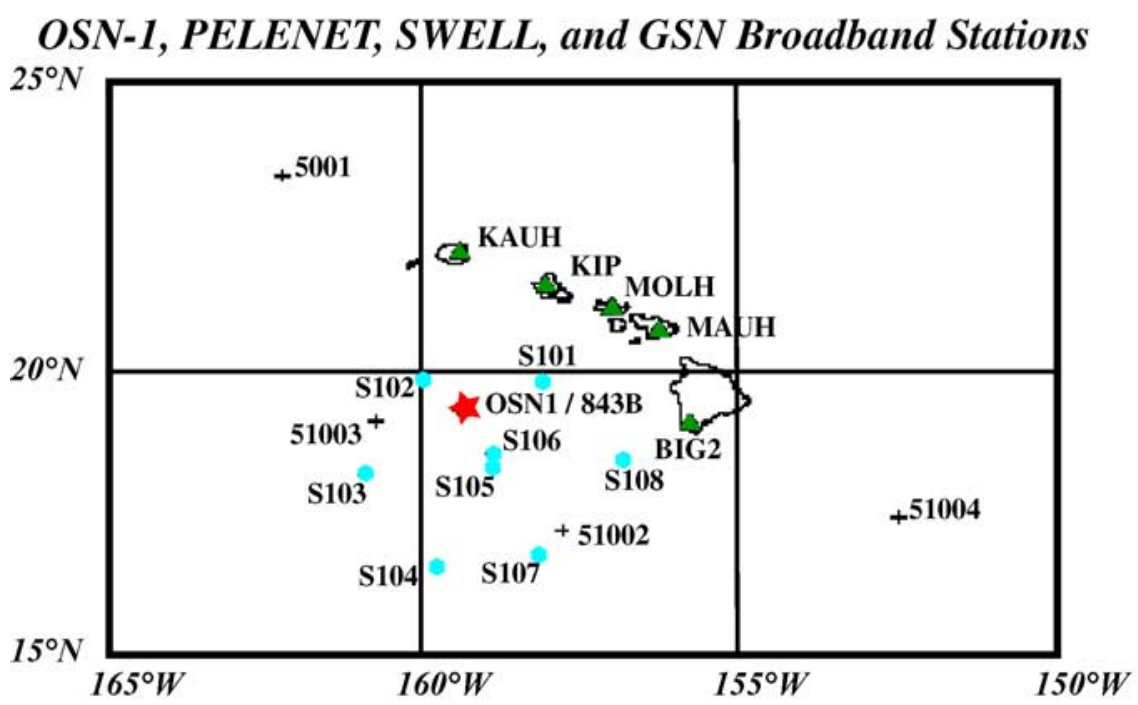

Figure 2. OSN-1 (ODP Site 843B) is about $225 \mathrm{~km} \mathrm{SW}$ of Honolulu. Located around the drill site are four NOAA weather buoys (the plus signs labeled 51001, 51002, 51003 and 51004) which provided sea state, wind speed and direction and other meteorological data during the four month recording phase of the OSN Pilot Experiment. Broadband stations on the Hawaiian Islands (the temporary network, PELENET [Wolfe et al., 1998], and the GSN station, KIP) are shown by green triangles. An array of eight "L-CHEAPO" broadband hydrophones (labeled S101 to S108) were also deployed during the OSNPE [Laske et al., 1999]. Data from the "L-CHEAPO" instruments are not discussed in this paper.

received field; (10) in the case of shallow buried seismometers, the aspect ratio and density of the sensor; (11) electrical system noise from preamplifiers, digitizers, power supplies and recorders; electrical cross-talk in the electronics or cables; mechanical vibrations from recorders; (12) variation with time of the ambient noise; (13) geographic variations of noise (Pacific versus Atlantic Ocean; variations with latitude and weather).

[13] An evaluation of the best sensor must be made in the context of a given application and costs. We need to evaluate signal-to-noise for signals of interest. Ambient noise may decrease (or increase) with depth below the seafloor, but signal strength may also decrease (or increase) [Duennebier et al., 1987b]. Enough signal events and noise intervals need to be observed to provide a statistically meaningful result. A single observation of an earthquake, for example, is not enough. Observations over prolonged periods of time, simultaneously on different configurations of sensor, such as on the OSNPE are necessary to resolve the trade-offs between many time-dependent factors. It had been estimated that a continuous acquisition of data over a three month period would be necessary to ensure a sufficient number of seismic events to evaluate a system.

\section{Equipment and Operations}

[14] The OSNPE was carried out in ODP Hole 843B (also called OSN-1) which was drilled by the D/V JOIDES Resolution on ODP Leg 136 [Dziewonski et al., 1992]. The hole is $225 \mathrm{~km}$ southwest of Oahu (Figure 2). Operations were carried out on a deployment cruise on the R/V Thompson from January 3 to February 11, 1998 [Stephen et al., 1998a] and on a recovery cruise on the R/V Melville from June 11 to 20, 1998 [Stephen et al., 1999a]. In addition to the three configurations of broadband seismometers (seafloor, shallow buried and borehole) data were acquired on three conventional Ocean Bottom Seismometers with $1 \mathrm{~Hz}$ geophone sensors, on differential pressure gauges, on a conventional hydrophone and on a current meter. The locations of the various seismic systems deployed in and around OSN-1 are shown in Figure 3.

[15] The borehole seismometer was a Teledyne KS54000 similar to the sensors used in the global IRIS IDA (International Deployment of Acceler- 


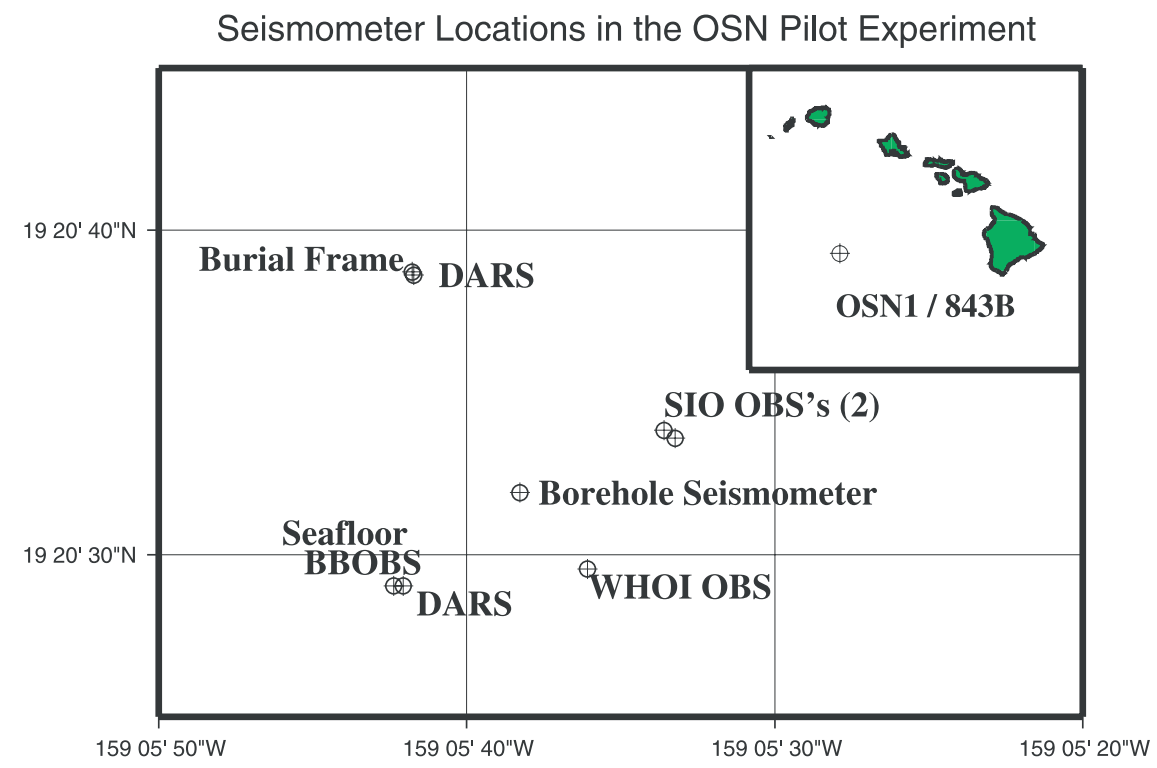

Figure 3. In addition to a buried broadband seismometer (Buried BBOBS and DARS) and a seafloor broadband seismometer (Seafloor BBOBS and DARS), three conventional VLF OBS's (two SIO-OBS's and a WHOI OBS) were deployed around the borehole seismometer in OSN-1. (OBS, Ocean Bottom Seismometer; BBOBS, Broadband Ocean Bottom Seismometer; DARS, Data Acquisition and Recording System; VLF, Very Low Frequency; SIO, Scripps Institution of Oceanography; WHOI, Woods Hole Oceanographic Institution).

ometers) and GSN networks. It was placed in the borehole using the MPL/JOI Wire line Reentry System [Spiess et al., 1992; Spiess et al., 1998]. The schematic in Figure 4 outlines the procedure for installing the borehole seismic system in an existing borehole on the seafloor from a conventional, nondrilling, research vessel. The ship is maintained within a $10 \mathrm{~m}$ watch circle by dynamic positioning and Global Positioning System navigation. Acoustic transponders on the seafloor assist in locating the borehole package relative to the reentry cone. In addition to the seismometer and clamping arms, the borehole package has a camera and lights (Figure 5) to assist in locating the cone. Once reentry is completed the system is lowered until the data recording package (Figure 6) lands in the cone. The Control Vehicle (Figure 7) has propulsion and additional navigational aids to manipulate the string near the seafloor. Once the system has been tested in place, the tether at the top of the recording package is released and the Control Vehicle returns to the surface. Figure 8 shows the data recording package sitting in the reentry cone at OSN-1 after the tether has been disconnected. Recovery of the recording package is carried out with a grappling hook attached to the bottom of the Control Vehicle. At OSN-1 the water depth was $4407 \mathrm{~m}$, the reentry cone was $5 \mathrm{~m}$ across and the borehole seismometer was emplaced $248 \mathrm{~m}$ below the seafloor (Figure 9).

[16] The seafloor and shallow buried sensors were Guralp CMG-3T seismometers. The sensors were emplaced in separate pressure housings from the batteries and data acquisition electronics. To ensure that the seafloor broadband seismometer did not sink into the sediments it was placed on a flat plate (Figure 10). The recording systems for both the seafloor and shallow buried broadband seismometers were essentially identical (Figure 10). The recording packages were separated about $12-20 \mathrm{~m}$ from the sensors to ensure that any vibrations of the recording package frame would not contaminate the seismic signals. The buried broadband seismometer was pushed about $1 \mathrm{~m}$ into the seafloor from a burial frame (Figure 11) [Wooding et al., 2001]. After installation, the burial frame was recovered to the ship leaving the buried seismometer and the recording package on the seafloor.

[17] The efforts of the group from the Scripps Marine Physical Laboratory were essential to the 

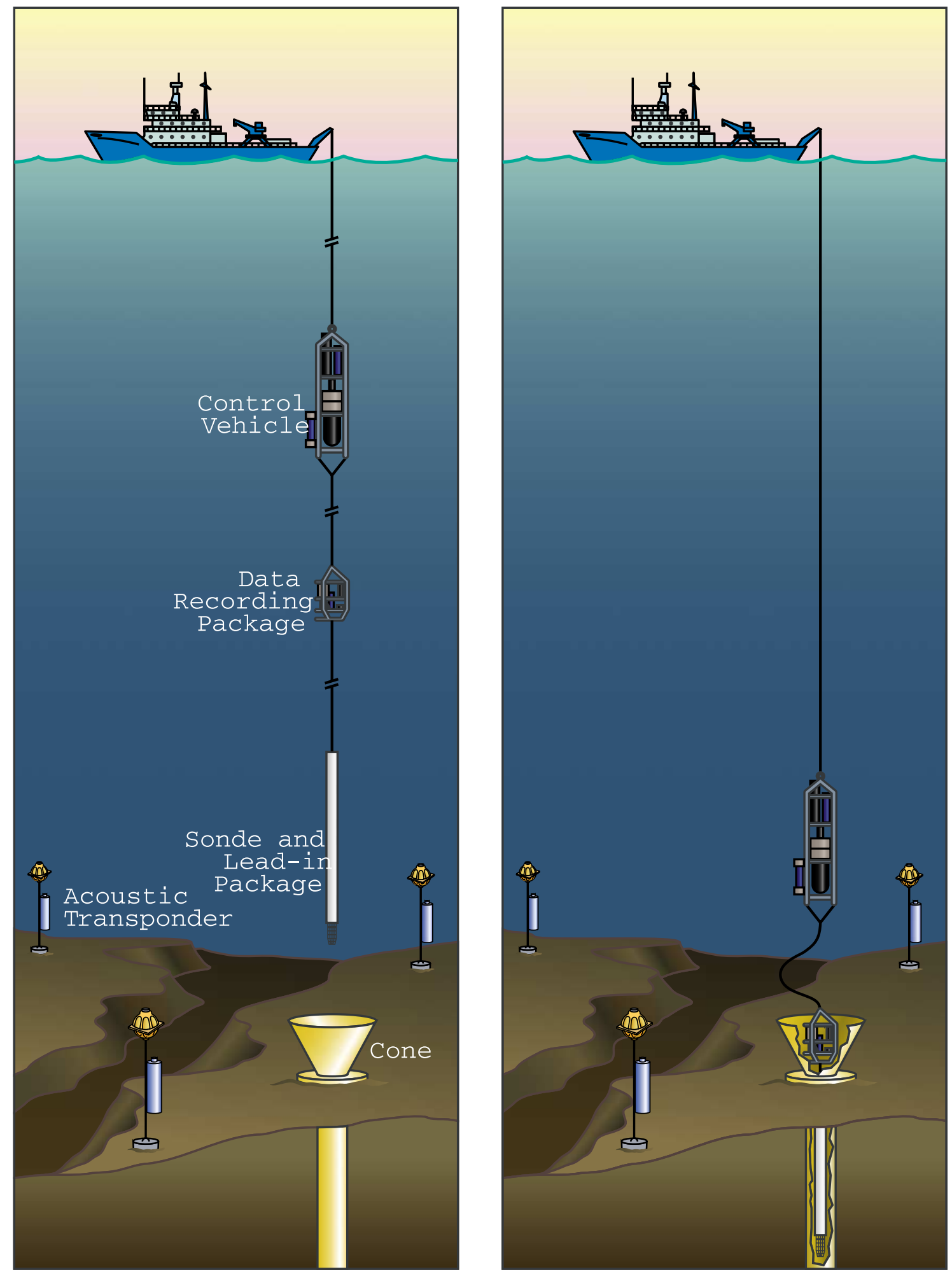

Figure 4. This schematic diagram shows the configuration of equipment used in a wire line deployed borehole seismic system. The BroadBand Borehole Seismic System $\left(\mathrm{B}^{3} \mathrm{~S}^{2}\right)$ consists of a sonde and lead-in package, containing a Teledyne KS54000 and the camera and lights for reentry, and a data recording package, which sits in the reentry cone, for autonomous data acquisition. The thruster, or control vehicle, is used to maneuver the sonde into the borehole. One advantage of this system over other ocean bottom seismometer systems is that the ship remains tethered to the seafloor system after deployment and data can be acquired onboard ship prior to releasing the tether. 


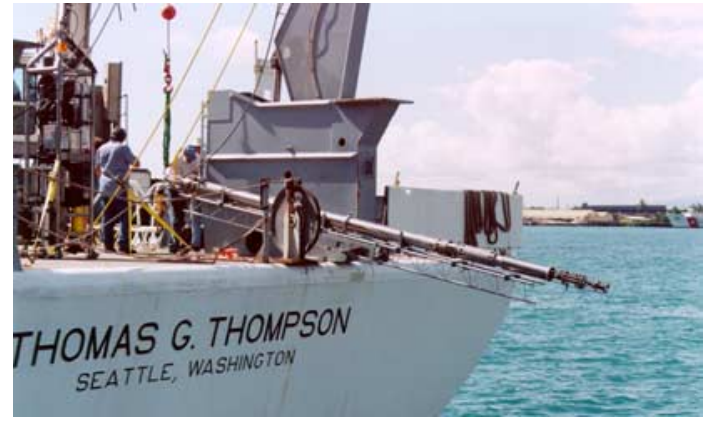

Figure 5. The borehole seismometer was deployed from a "teeter-totter" on the fan tail of the R/V Thomas G. Thompson. The lead-in package (TV, lights and navigation transponder) is about $2 \mathrm{~m}$ long and can be seen at the right at the end of the seismometer. Three clamping arms were used at the top and bottom of the seismic sensor package to lock the seismometer into the casing. The seismic sensor package consists of a Teledyne KS54000 in a titanium pressure housing.

success of the OSNPE. Their operations fell into three categories: control vehicle and reentry operations, wire line borehole logging and wire line packer tests. These operations are discussed further below. On the OSNPE all three broadband systems benefited from the wire line reentry and control vehicle capabilities. The wire line logging capability provided information on the condition of Hole 843B prior to installing the borehole seismometer. It was clear prior to the OSNPE that a packer would be necessary to block fluid flow in the hole which would be a source of noise on the borehole seismometer. When drilled on ODP Leg 136 the hole had been cased through the sediment and into the top of basement, but below the casing there was $54 \mathrm{~m}$ of open hole. Flow from or into the porous upper basement has been observed in many ODP holes [Morin et al., 1992]. A borehole packer was developed at Scripps MPL that could be installed at the bottom of the casing but since the packer was not successfully installed on the OSNPE a likely explanation of the anomalous noise observed on the borehole sensor at long periods (see below) is fluid flow around the seismometer.

\subsection{Control Vehicle and Reentry Operations}

[18] The Control Vehicle (CV, Figure 7), which was developed and deployed by the Scripps Marine
Physical Laboratory, was used in three modes during the OSNPE: for observation of seafloor features and equipment, for equipment launch and recovery, and for power supply and telemetry between seafloor units and the ship. The reentry probe (also called the logging tool, Figure 12) and the lead-in package (LIP, Figures 5 and 13) were secondary units. The LIP was used for navigation and video while placing the seismometer and packer into the cone. On the OSNPE the system made four entries of OSN-1 with various payloads.

[19] The first phase of operations was the deployment of the transponder net. The net consisted of three transponders which were located on a circle about $1 \mathrm{~km}$ radius from the presumed cone location, and which were tethered about $40 \mathrm{~m}$ above

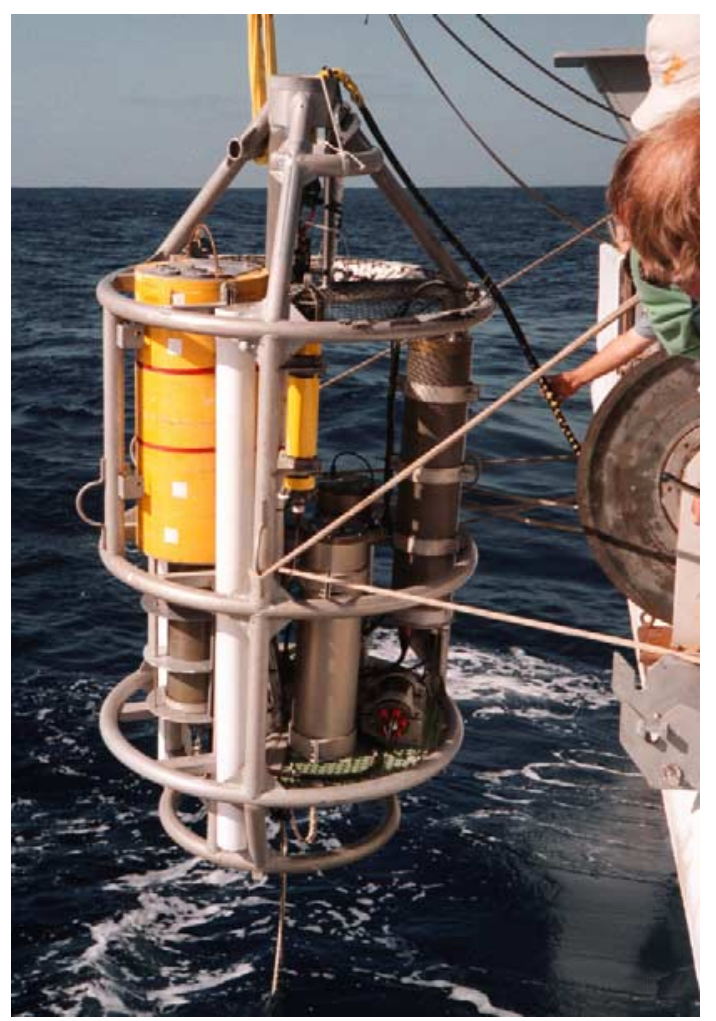

Figure 6. The bottom instrument package consists of a frame that is designed to sit in the reentry cone. It contains the bottom control unit (the gray housing in the upper right), the data recording unit (in a sleeve of yellow syntactic foam on the left) and three large housings of lithium batteries (one of the battery housings can be seen in the lower foreground). Above the battery housing is one of two yellow acoustic transponders. 


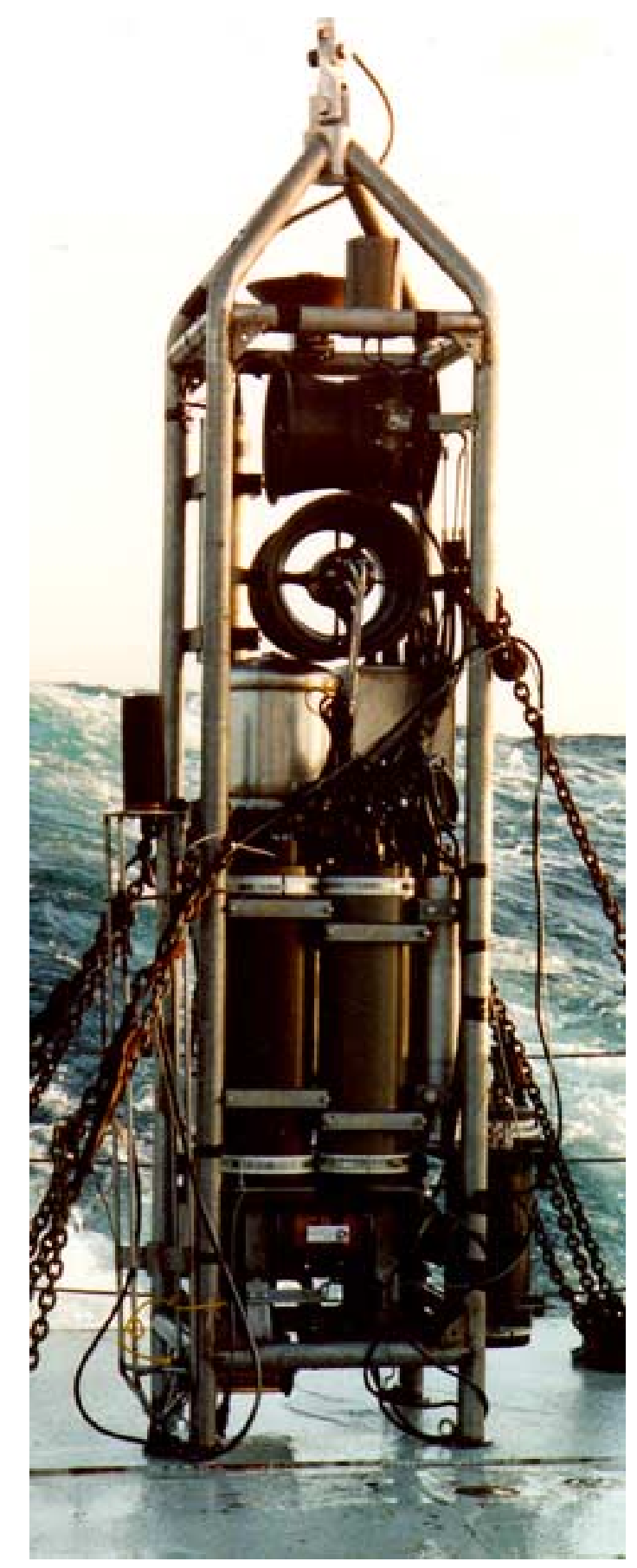

Figure 7. The control vehicle (CV) contains a thruster, up and down looking sonar, a navigation transponder and telemetry electronics.

the seafloor. The underlying philosophy was to have relatively short acoustic travel times and short enough tethers that the transponders would not move more than a few meters in response to near bottom currents. The transponders were also placed to provide a simple coordinate system in which the transponder ranges themselves could be used as direct indicators of vehicle position for operations near the cone. One unit was thus put directly north and one unit (with current meter) directly east of the initial assumed location of the cone. The third transponder provided a backup capability and was located southwest of the cone.

[20] With the transponders in place and the ship in dynamic positioning mode (DP) at the cone coordinates, the $\mathrm{CV}$ was deployed and lowered to the seafloor. The cone was initially located with the $\mathrm{CV}$ scanning sonar and as the $\mathrm{CV}$ maneuvered to within a few meters of the cone it came into view on the video. Transponder ranges were recorded while the CV was held steady over the target for about 20 minutes. The cone was clear, although there were traces of sediment on the sonar reflectors (Figure 14).

[21] Each of the four subsequent entry operations was carried out in three steps:

[22] 1. Before paying out the last $2 \mathrm{~km}$ or more of wire, the ship was put in the best known surface position over the cone and held there in DP while the last wire was paid out. DP station keeping was quite good, holding almost always within $5 \mathrm{~m}$ of the position assigned, but usually better than that.

[23] 2. Once the $\mathrm{CV}$ was within about $50 \mathrm{~m}$ of the seafloor its ranges to the north and east transponders were measured (using direct transmis-

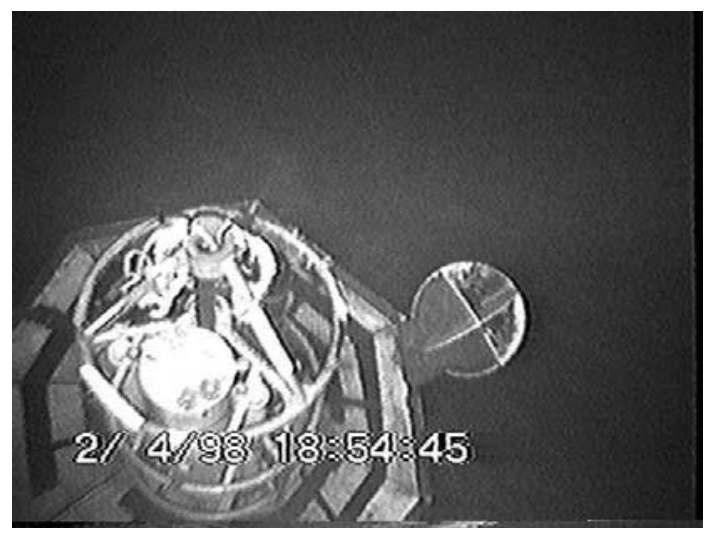

Figure 8. The bottom instrument package is shown in the reentry cone at ODP Hole $843 \mathrm{~B}$ prior to leaving the site for the four month autonomous recording period. 


\section{Depth Summary at Hole 843B (OSN-1)}

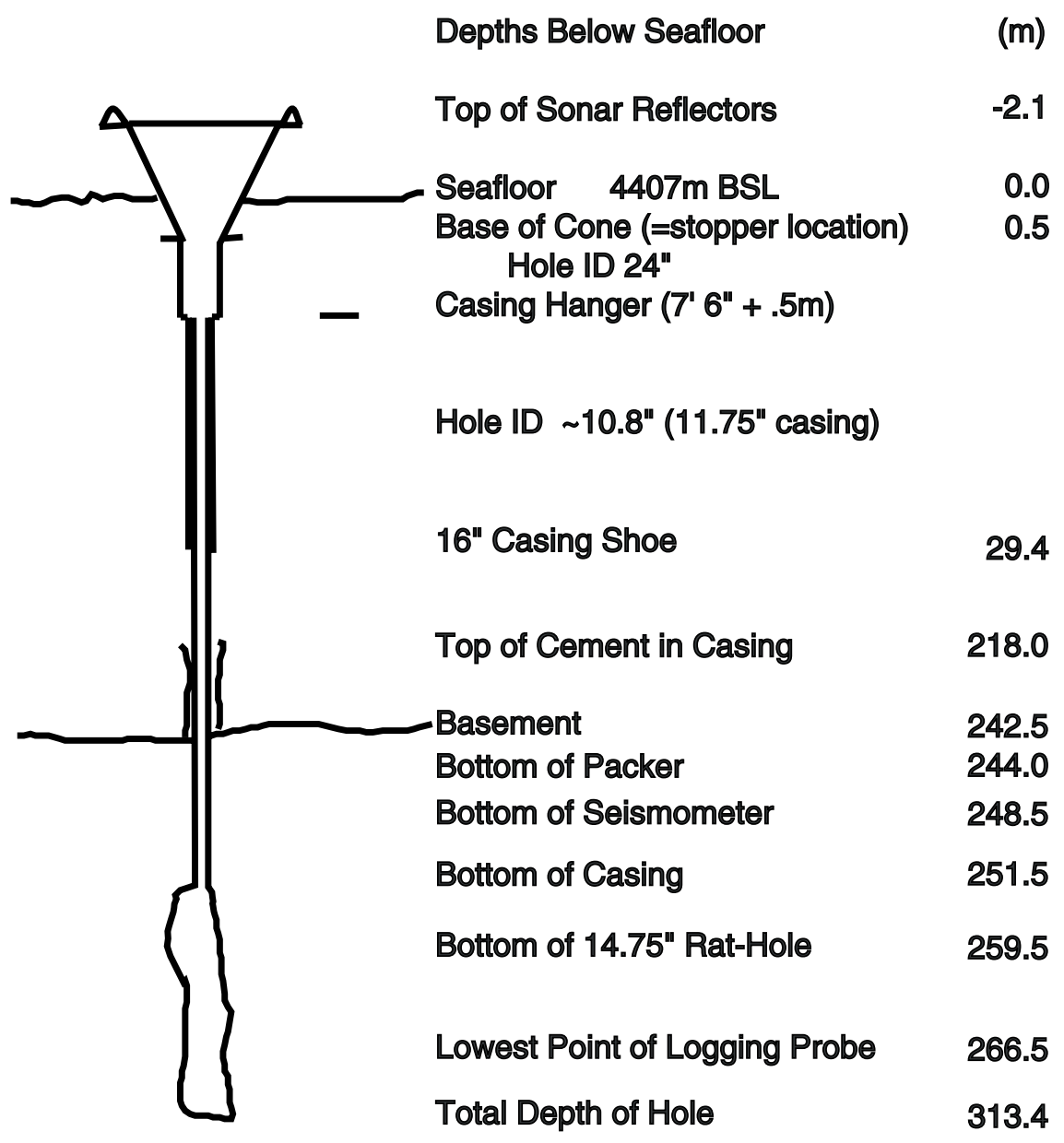

Figure 9. This figure summarizes the significant depths in Hole $843 \mathrm{~B}$ for the OSNPE operations. There was $242 \mathrm{~m}$ of sediment and the borehole sensor was placed within $3 \mathrm{~m}$ of the bottom of the casing which was $9 \mathrm{~m}$ into basement.

sion/reception at the LIP or logging tool - a capability not implemented in previous operations). The difference between those ranges and the ranges for the "on-top" position (over the cone) were determined, were converted to latitude and longitude differences and were used to alter the ship's position.

[24] 3. Within 15 to $30 \mathrm{~min}$ the LIP (or the logging tool) would be lowered to about $10 \mathrm{~m}$ above the seafloor (amount of wire to do this was repeatable to within about a meter) and the cone would appear in view as the LIP moved to the correct range values. No thrust at the $\mathrm{CV}$ was used. Once the TV picture showed the position steady close to the center of the cone the main wire was paid out and the vehicle entered the cone. The surface swell-induced ship motion usually resulted in one bounce on the way in. Wire payout was usually 15 to $20 \mathrm{~m} / \mathrm{min}$ going in and 10 to $20 \mathrm{~m} / \mathrm{min}$ going down the hole.

[25] Travel down the hole was usually smooth, as recorded by the pressure gauge, showing the expected wave induced oscillations superposed on the general downward or upward trend. The one exception was during the packer launch when the payload stopped descending at about $30 \mathrm{~m}$ into the hole. The wire was pulled up a few meters and smooth descent resumed. This hang-up may have resulted in a quick stop for the upper part of the two-part assembly and a resulting jerk in the 


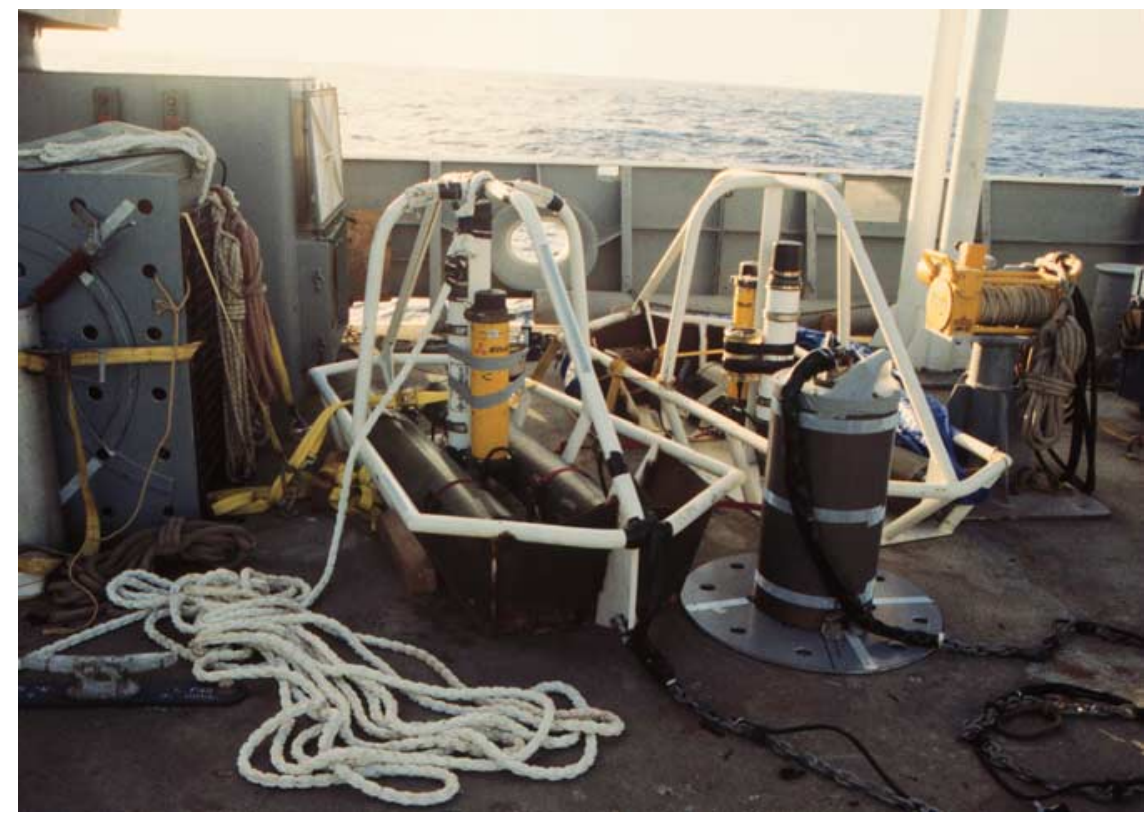

Figure 10. The seafloor BBOBS (Broadband Ocean Bottom Seismometer) is shown next to the two DARS (Data Acquisition and Recovery System) frames on deck. The white rope is the soft tether which accommodates heave after landing the package on the seafloor.

connecting wire/weak link may have caused it to part at this time.

[26] The offset between the LIP and the hole varied from one lowering to the next. The largest offset was about $20 \mathrm{~m}$ and the smallest about $5 \mathrm{~m}$ (in that case the edge of the cone was in view from the start in the wide-angle TV picture). The variable nature of the offset, depending on the current profile through the entire water column, was well docu-

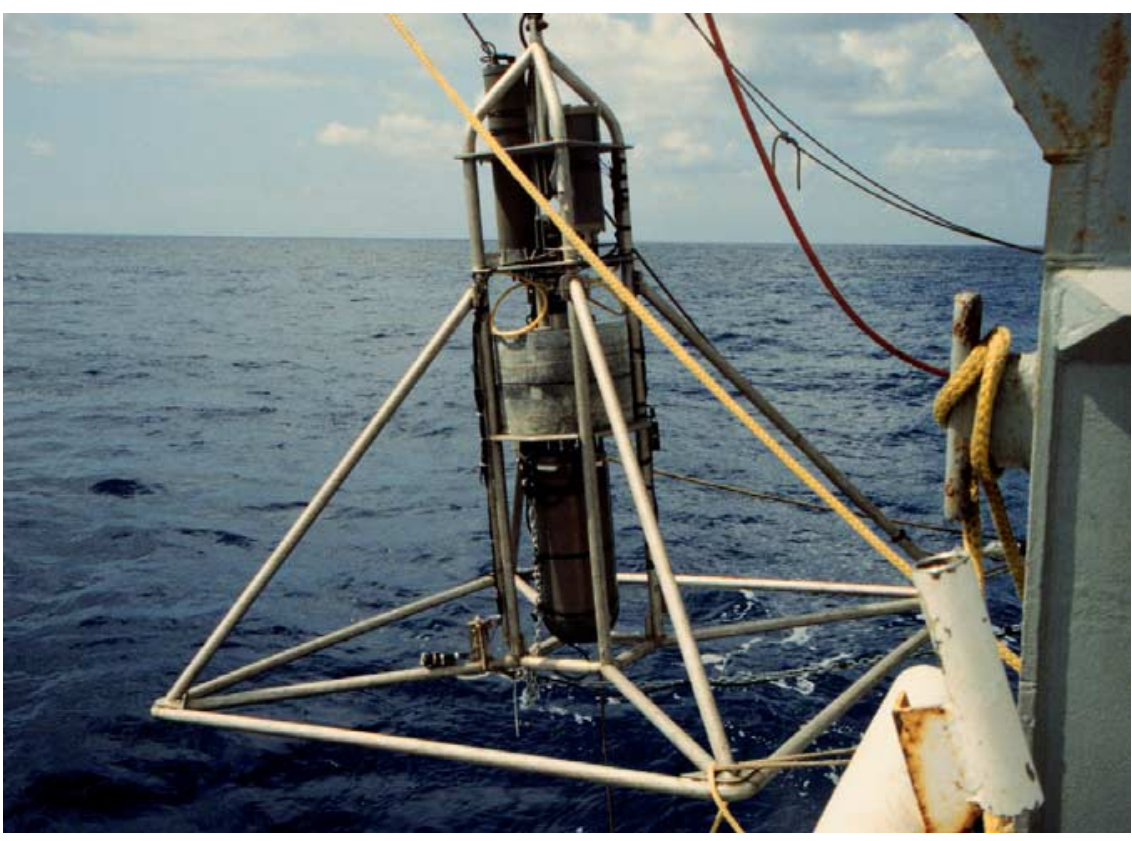

Figure 11. The buried BBOBS seismometer is shown in the burial frame as it is deployed off the fantail of the R/V Thompson. The burial system is described further in Wooding et al. [2001]. 


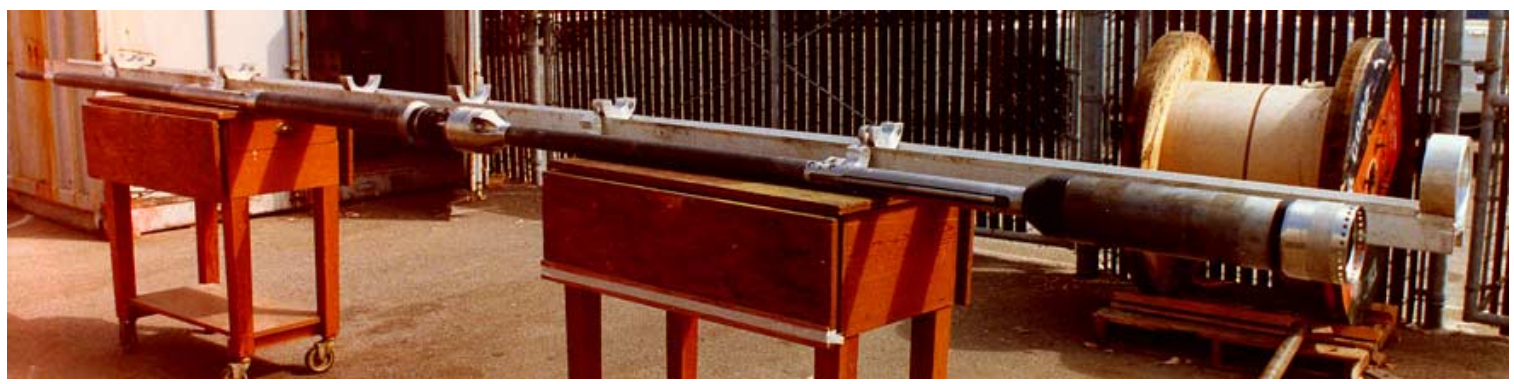

Figure 12. The reentry probe (also called the logging tool) used to test the hole prior to installation of the borehole seismometer is shown. Its components are: a low light level TV, 80 watts of illumination, two three arm calipers, a platinum resistance thermometer, a pressure gauge and a navigation transponder.

mented in a test during which the ship was held in DP at a point about $50 \mathrm{~m}$ from the hole. During 24 hours of recorded transponder navigation (with no thrust on the CV and with the height off the bottom intentionally varying between 60 and $120 \mathrm{~m}$ to minimize working the wire always at one spot) the CV moved slowly in a box about 20 by $30 \mathrm{~m}$, centered about $40 \mathrm{~m}$ from the cone.

[27] The CV in the observational mode used parallel TV channels: one slow scan telemetered to the ship and the other recorded in the CV. (This duality has since been circumvented by conversion to fiber optic telemetry [de Moustier et al., 2000].) The observational mode was used to initially locate and record the position and condition of the cone, to document the tether pile on the seafloor about $40 \mathrm{~m}$ from the cone (following the release of the tether to the Bottom Instrument Package - BIP), and to view the BIP sitting in the cone (Figure 8). The CV was also used in the observation mode to videotape the vicinity of the buried seismometer and its DARS (Data Acquisition and Recording System) following the second installation of this system. The DARS was spotted only about $15 \mathrm{~m}$ from its position on the previous deployment (based on transponder ranges in the two instances). The imprint of the burial frame (Figure 11) on the seafloor and the connecting cable running to it (as indicated by the line of dots from the reflecting tape on the cable) were clearly visible. The seismometer package was covered with enough sediment that its reflecting tape was not visible. There was also a suggestion of an image of a second

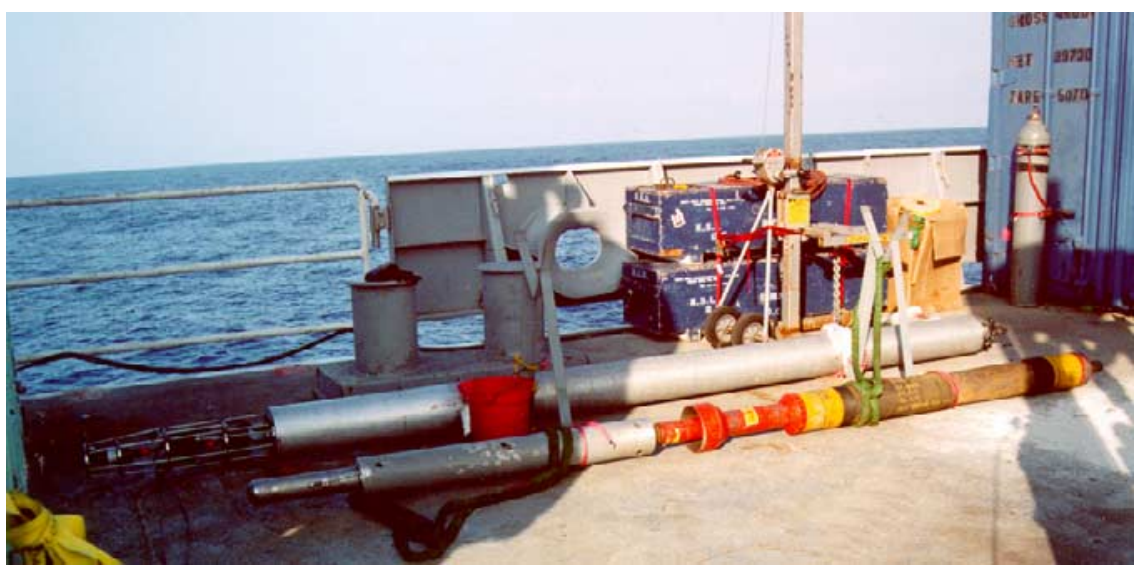

Figure 13. The borehole packer system was intended to block fluid flow in the hole that might cause noise on the borehole seismometer. As configured for deployment by the wire line reentry system it consisted of two units. The lower unit with the packer, its setting tool, hydraulic pump, motor and pressure gauge is in the foreground with the yellow and red sections. Behind it is the upper unit with the lead-in package and a reservoir of hydraulic fluid for expanding the packer. The lead-in package (LIP) can be seen to the left of the hydraulic unit. This system was tested during the OSNPE. 


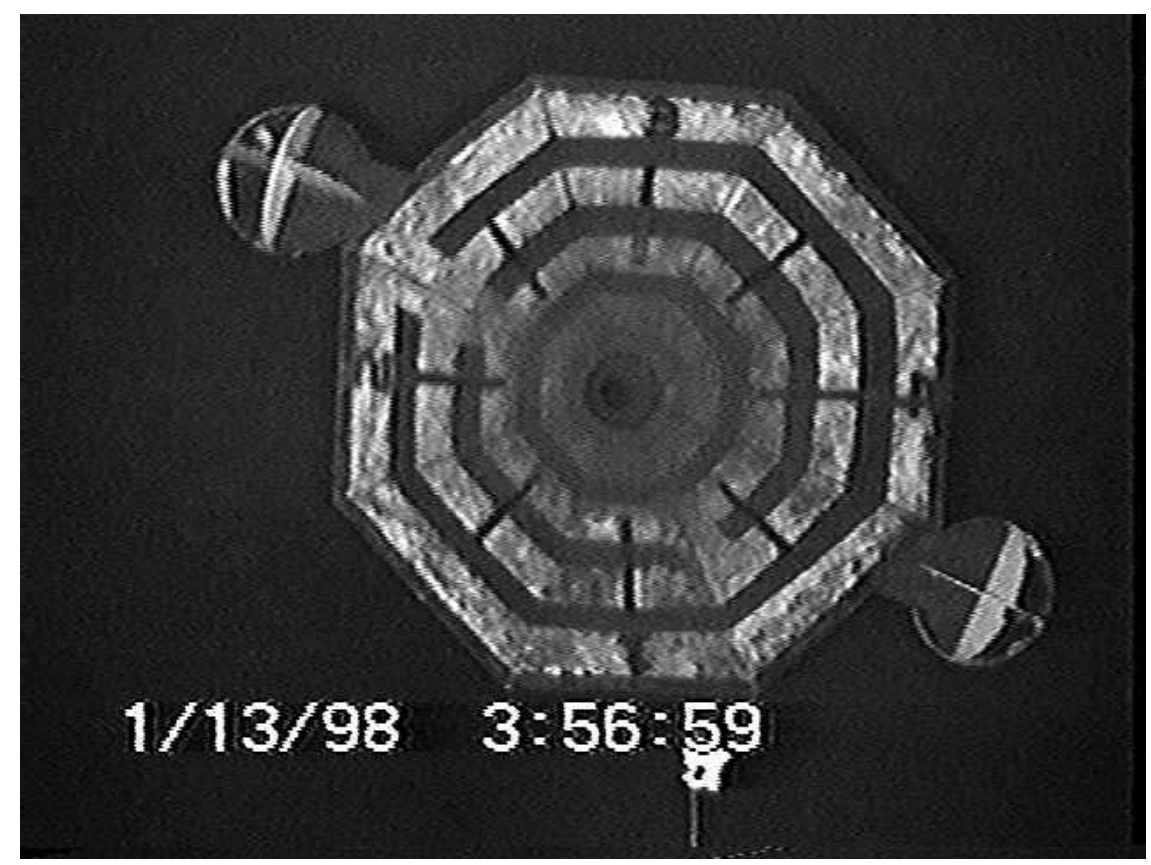

Figure 14. The reentry cone at OSN-1 (ODP Hole 843B) as observed from the Control Vehicle prior to OSNPE reentry operations.

imprint of the burial frame from the prior deployment, since the two were very close together.

[28] In the equipment placement and recovery mode the CV was used to deploy the seafloor seismometer and its data recording sled (DARS), placing the seismometer on the bottom, moving off, and placing the DARS about $12 \mathrm{~m}$ away (the cable joining the two was $20 \mathrm{~m}$ long). Two days later, when it had been determined that the seismometer was not working, the $\mathrm{CV}$, equipped with a retrieval hook about $8 \mathrm{~m}$ below it, was used to recover the seafloor seismometer and its DARS. (The hook had engaged the DARS in such a manner that two prongs were in contact with the sled frame. During the course of the trip up to the ship one prong was bent over and the load shifted to a single prong. With this in mind it was decided that the replacement hooks for the June recovery would be built using 1 in $(0.0254 \mathrm{~m})$ rather than the present $7 / 8$ in $(0.0222 \mathrm{~m})$ bar stock.) The second deployment was carried out in the same manner as the first. The seismometer case again landed vertically, although the base plate had been substantially reduced in area from the first launching. The
$\mathrm{CV}$ was lowered to camera range to verify that all was well prior to retrieving the $\mathrm{CV}$ on board.

[29] Finally, the CV was used to recover the buried seismometer and its DARS. In this case, the position of the DARS was uncertain at the level of over $100 \mathrm{~m}$. The DARS had a transponder on it, listening to $11 \mathrm{kHz}$ and replying at $10 \mathrm{kHz}$. We widened the receiving band in order to hear its replies that we hoped would be made to our $11 \mathrm{kHz}$ interrogations. This approach failed, probably because our transmitted pulses were not as long as the DARS transponders required. We then began a video search pattern with lines about $10 \mathrm{~m}$ apart and 80 to $100 \mathrm{~m}$ long at right angles to the track. On the sixth pass we saw the DARS. The CV with its retrieval hook recovered the DARS and buried seismometer. During pullout the tension meter briefly showed $17,000 \mathrm{lbs}(7711 \mathrm{~kg})$. Given the marginal performance of the light weight hook in the prior recovery, we used one of two heavy-duty units (to which spring latches had been added by the ship's welder the night before the recovery). On recovery the buried seismometer was still mudcovered. 
[30] Overall, the CV performed in reliable fashion. Ten lowerings (two to find and log the hole, two for the packer project, and two each for the downhole seismometer, the seafloor seismometer and its DARS, and the buried seismometer and its DARS) were made to within visual distance of objects on the seafloor in water depths of about $4400 \mathrm{~m}$ depth. None of the lowerings were terminated because of a problem with the $\mathrm{CV}$.

\subsection{Borehole Logging Operation and Results}

[31] The first operation after locating the cone in transponder coordinates was to determine the condition of the hole. The basic logging tool (Figure 12) was essentially the same unit as was used in the 1989 LFASE (Low Frequency Acoustic-Seismic Experiment) expedition [Spiess et al., 1992; Stephen et al., 1994]. Its components are: a low light level TV, 80 watts of illumination, two three arm calipers, a platinum resistance thermometer, and a pressure gauge. The original tool included a hydrophone to receive transponder replies. On the OSNPE this system was augmented to include a transponder interrogation capability as well. Relying on triggering transponders from some other point (such as the ship or $\mathrm{CV}$ ) is a more cumbersome and less accurate procedure. The physical components, with the exception of a new, longer electronics section, were those procured in 1988 with LFASE funding, and had not been used in a hole since that time.

[32] The tool was rigged with $260 \mathrm{~m}$ of 0.322 in $(0.0082 \mathrm{~m})$ coaxial cored electromechanical cable terminated at the upper end with a small "stopper" plate and attached at the upper end to $250 \mathrm{~m}$ of soft tether. The soft tether was in turn terminated at the $\mathrm{CV}$ which was suspended on the ship's 0.68 in $(0.0173 \mathrm{~m})$ main electromechanical cable. As in previous operations, an open frame rode on the upper part of the logging tool. After reentry the frame sits in the bottom of the cone, providing a fairlead through which the 0.322 in wire could ride into the hole without abrasion at the bottom of the cone. This open frame, sometimes called the leadin guide, was also the resting point for the "stopper" plate at the top of the 0.322 in wire. The stopper plate limits the travel of the tool down the hole and provides a datum (given the measured length of the 0.322 in wire) of the downhole depth at the start of the upward logging run. The length of $260 \mathrm{~m}$, the maximum depth of penetration in the hole, was chosen to be $10 \mathrm{~m}$ longer than the cased section of the hole and drilling reports indicated that the casing was $250 \mathrm{~m}$ long. It was necessary to confirm the depth to the end of the casing from the "stopper" in order to define the wire lengths for the equipment installation. There also was some concern about the minimum hole diameter, since two caliper logs made by the drill ship did not agree - one showing a smaller diameter than expected.

[33] The position over the hole was easily acquired (see the section 3.1) and the tool was run in. There was enough swell-induced heaving motion that the tool bounced twice before going into the hole, and the TV was disabled at this stage. Once in the hole we paid out wire at $10 \mathrm{~m} / \mathrm{min}$ and the tool continued down in expected fashion, stopping as the upper end of the 0.322 wire reached the lead-in guide in the bottom of the cone. Clearly, the first goal of the logging operation had been achieved the hole was open, at least to the $18 \mathrm{~cm}$ maximum diameter of the tool, to $260 \mathrm{~m}$ depth.

[34] The calipers were then opened and the run up the hole started at $5 \mathrm{~m} / \mathrm{min}$. Initially the calipers performed in a consistent manner, but as the run progressed they gave erratic results. Upon retrieval of the tool on deck it was discovered that the caliper arms had been damaged during the run up the hole. In retrospect, use of a bowstring caliper, as implemented in subsequent operations [Becker et al., 2001], would have been more appropriate.

[35] The caliper log (Figure 15) clearly showed the large diameter washout just below the casing, with a sharp transition into the expected casing diameter in agreement with one of the logs made just after drilling. These data were used to set the length of the cable between the sonde and the bottom instrument package (BIP) and to place the sonde as far into the cased section of basement as possible.

[36] After recalibration upon return to San Diego, the temperature log also gave good results 


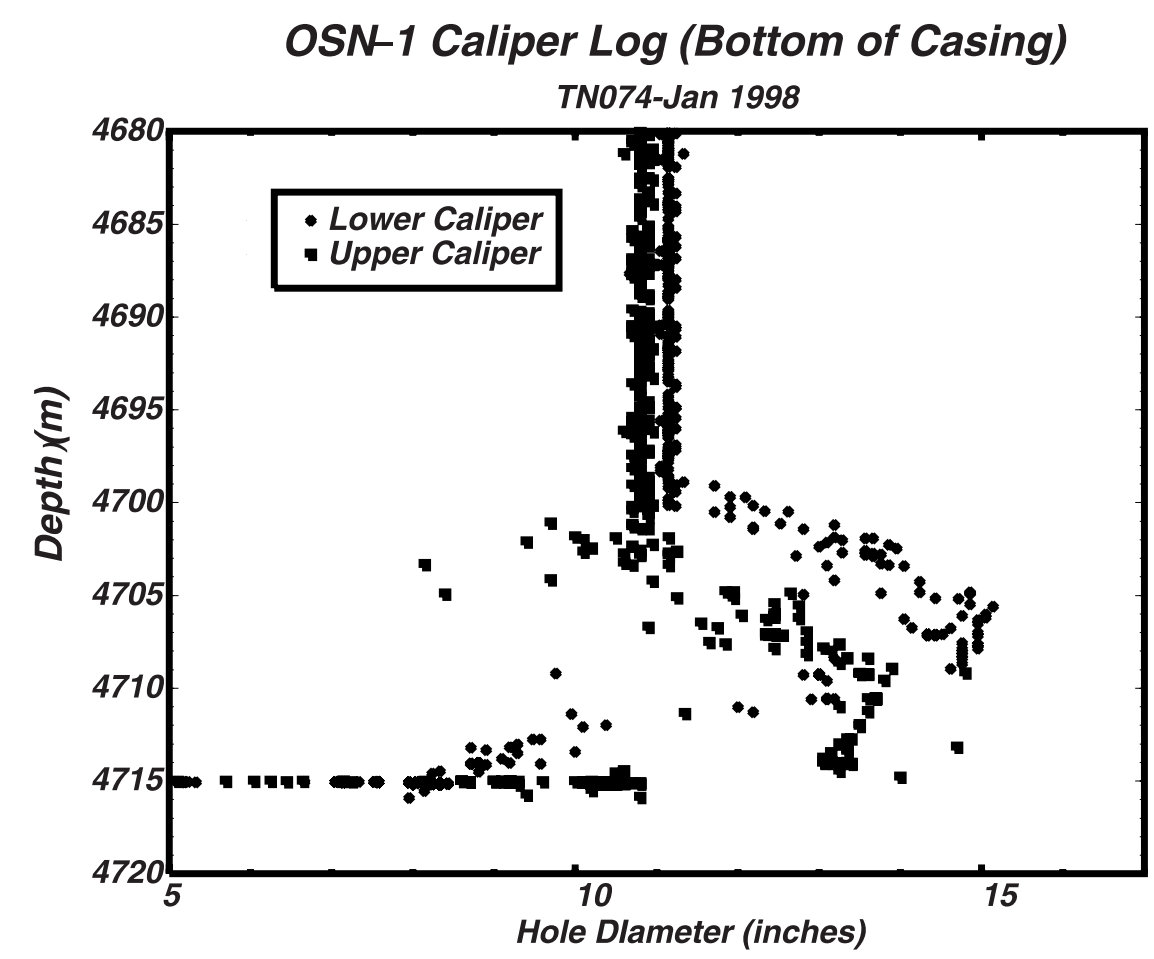

Figure 15. The caliper log shows the diameter of the hole opening to almost 15 inches just below the casing (with an 11 inch diameter) at about $4700 \mathrm{~m}$.

(Figure 16). The curve in the lower part of the hole shows a gradient that changes with depth. It is consistent with a model for equilibrium with a constant heat flow and with variations in heat conductivity compatible with reasonable values as a function of depth for sediment and basalt [Wiggins et al., 2002; Wiggins et al., 1999]. Unfortunately no values of thermal conductivity are reported from the drilling leg other than in the sediment at the top of the hole, and in the basement basalt.

\subsection{The Wire Line Packer Test}

[37] The principal piece of new wire line reentry technology on the OSNPE was the packer. Its purpose, as in other drill hole situations was to close the hole at some pre-determined depth, preventing borehole fluid flow that might create noise on the seismometer. Wire line packers are often used in conventional drilling operations and a hydraulically operated packer was commercially available. Gary Austin, from Scripps MPL, with consulting help, designed the downhole equipment to provide the necessary hydraulic power. A system that used water based oil as the working fluid was developed and an 8 in $(0.2032 \mathrm{~m})$ diameter cylindrical container was built to house a bladder capable of holding approximately 20 gallons of oil (Figure 13).

[38] It was essential that the TV, lights and transponder navigation system required for hole entry would be available for other entry operations after packing the hole. The downhole system was thus built in two sections. The lower section was the packer, with its attached setting tool, hydraulic pump, motor and pressure gauge. The upper section was the lead-in package (TV, lights, acoustic navigation, precision pressure gauge) with the hydraulic tank bolted above it. The two sections were connected by about a meter of strength wire, containing the electrical conductors to power and control the pump, paralleled by the low pressure hydraulic hose from tank to pump. This separation was needed to allow the TV camera and illumination above the packer assembly to have a useful field of view past the packer during entry. The packer was operated several times prior to the 


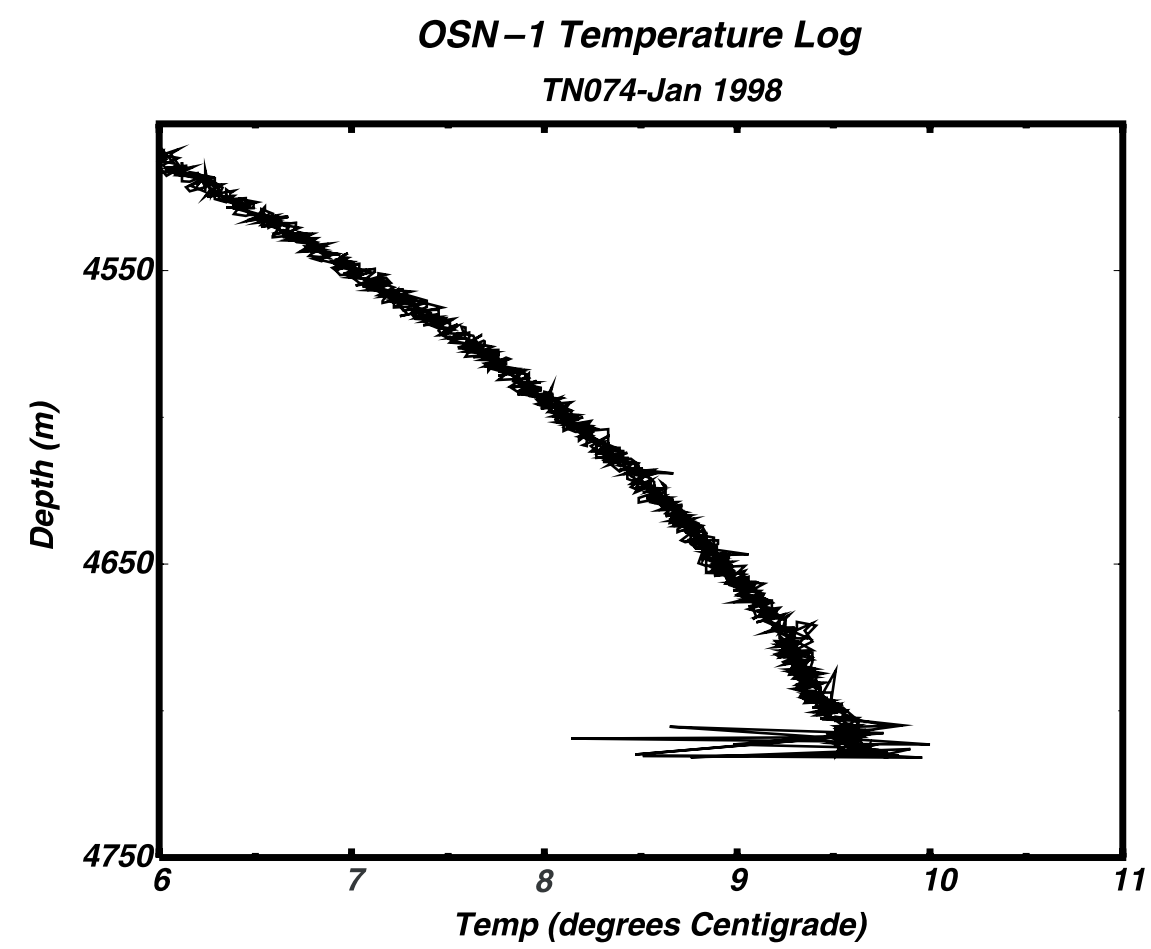

Figure 16. The temperature log in the well shows a progressively increasing temperature with depth. The profile is consistent with a model for equilibrium with a constant heat flow and with variations in heat conductivity compatible with reasonable values.

expedition and it was further tested at sea in the full configuration prior to placing it in the hole.

[39] It had been decided earlier that the short piece of logging cable connecting the two sections of the system would be connected at the packer/pump end with a standard oil field termination to facilitate fishing the section out of the hole at a later time if necessary. It was also decided to make that termination a $3500 \mathrm{lb}(1588 \mathrm{~kg})$ weak link to release the rest of the system if the pump should fail to finish the pressurizing and release cycle. Unfortunately during the lowering process after reentry the weak link separated leaving the packer assembly (but not the reservoir and LIP) in the borehole. A successful packer installation has since been carried out in a wire line CORK installation supporting hydrogeological investigations on the Costa Rica Rift [Becker et al., 2001].

\section{Data}

[40] All three of the broadband instruments recorded data continuously and autonomously on the seafloor from the time they were deployed in early February until late May or early June (at least 115 days). Sea state, wind speed, wave spectra, and atmospheric pressure during the OSNPE recording period were acquired on NOAA weather buoys (Figure 2). Bottom currents were acquired at the site on a current meter deployed with one of the navigational transponders. VLF seismic data were also acquired on three conventional OBS's. In addition to the OSNPE sensors an array of broadband hydrophones (L-CHEAPO - Low-Cost Hardware for Earth Applications and Physical Oceanography) was also deployed around OSN-1 for the SWELL Experiment [Laske et al., 1999]. The seafloor data was compared with broadband data on the Hawaiian Islands at the GSN station at Kipapa and on the PELENET temporary broadband array.

\subsection{Ambient Noise}

[41] Figures 17 and 18 show ambient noise spectra for the three components of the borehole sensor on days of quiet and rough sea state respectively. The 


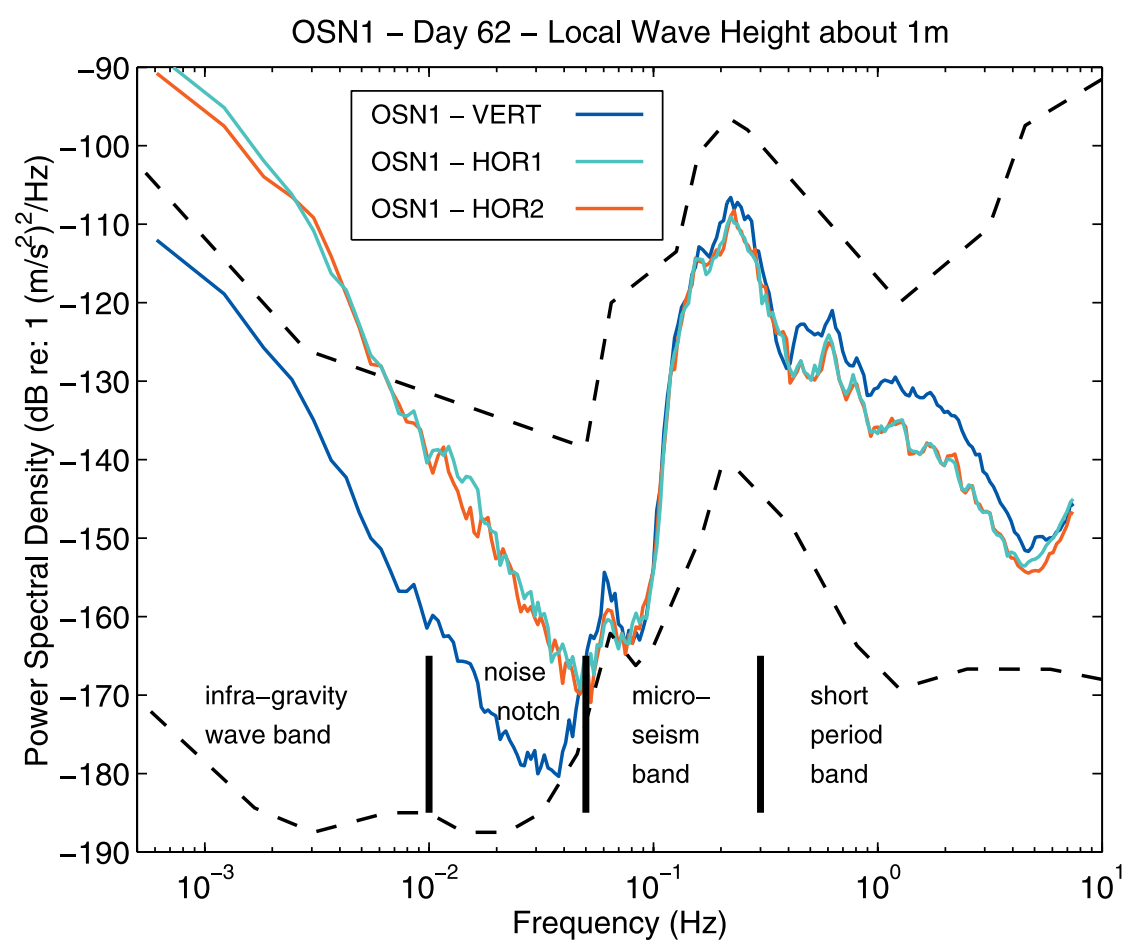

Figure 17. Spectra for the three components of the borehole sensor at OSN-1 are shown for a quiet day with wave heights less than $1 \mathrm{~m}$. Except for the horizontal components in the infra-gravity band, noise levels fall within the high and low noise models of Peterson (dashed black lines) [Peterson, 1993]. The principal frequency bands within the broadband spectra are labeled. (Unless otherwise stated, all spectra shown in this paper were computed on 32768 point data windows in a 131072 point block of data using Welch averaging with $75 \%$ overlap and Hanning tapered windows. Spectra were doubled to allow for power in the negative frequencies and were smoothed to approximately even spacing in log frequency using 64 frequencies per decade. The sample rate was 20 sps. Since ambient noise is very similar on both horizontal components often only one horizontal component will be displayed.)

major frequency bands of interest are labeled in Figure 17 and common features of ambient noise spectra are labeled in Figure 18. In contrast to many short period seafloor observations over the past 30 years the horizontal components are quieter than the vertical components at frequencies above the microseism peak. Except for the horizontal components in the infra-gravity band, noise levels fall within the high and low noise models of Peterson (dashed black lines) [Peterson, 1993]. (Infra-gravity waves are freely propagating ocean waves that occur at frequencies less than $0.04 \mathrm{~Hz}$ and are generated by nonlinear processes from wind-waves and swell [Webb, 1998; Webb et al., 1991].)

[42] The ambient noise behavior falls into four distinct frequency bands (Figure 17). In the infragravity band, $1-10 \mathrm{mHz}$, there is a strong tidal frequency dependence on the borehole sensor indicating that water flow in the hole may be exciting installation noise. The largest amplitude changes occur in the noise notch, $10-50 \mathrm{mHz}$, where vertical component levels vary from the almost the quietest ambient noise levels observed worldwide $\left(-185 \mathrm{~dB}\right.$ re: $\left.1\left(\mathrm{~m} / \mathrm{s}^{2}\right)^{2} / \mathrm{Hz}\right)$ to levels above $-120 \mathrm{~dB}$ re: $1\left(\mathrm{~m} / \mathrm{s}^{2}\right)^{2} / \mathrm{Hz}$ after an event like the Balleny Islands earthquake. (Strictly speaking events should not be studied with power spectral densities, but it is still an interesting observation.) The microseism band, $50-300 \mathrm{mHz}$, is characterized by three peaks (Figure 18). Levels of the single frequency microseism peak at $60 \mathrm{mHz}$ can increase $60 \mathrm{~dB}$ after a large earthquake. (It is interesting that this peak, often described in terms of sea state and ambient noise also appears in the spectra of earthquake events.) The levels of the two double frequency microseism peaks are much less variable 


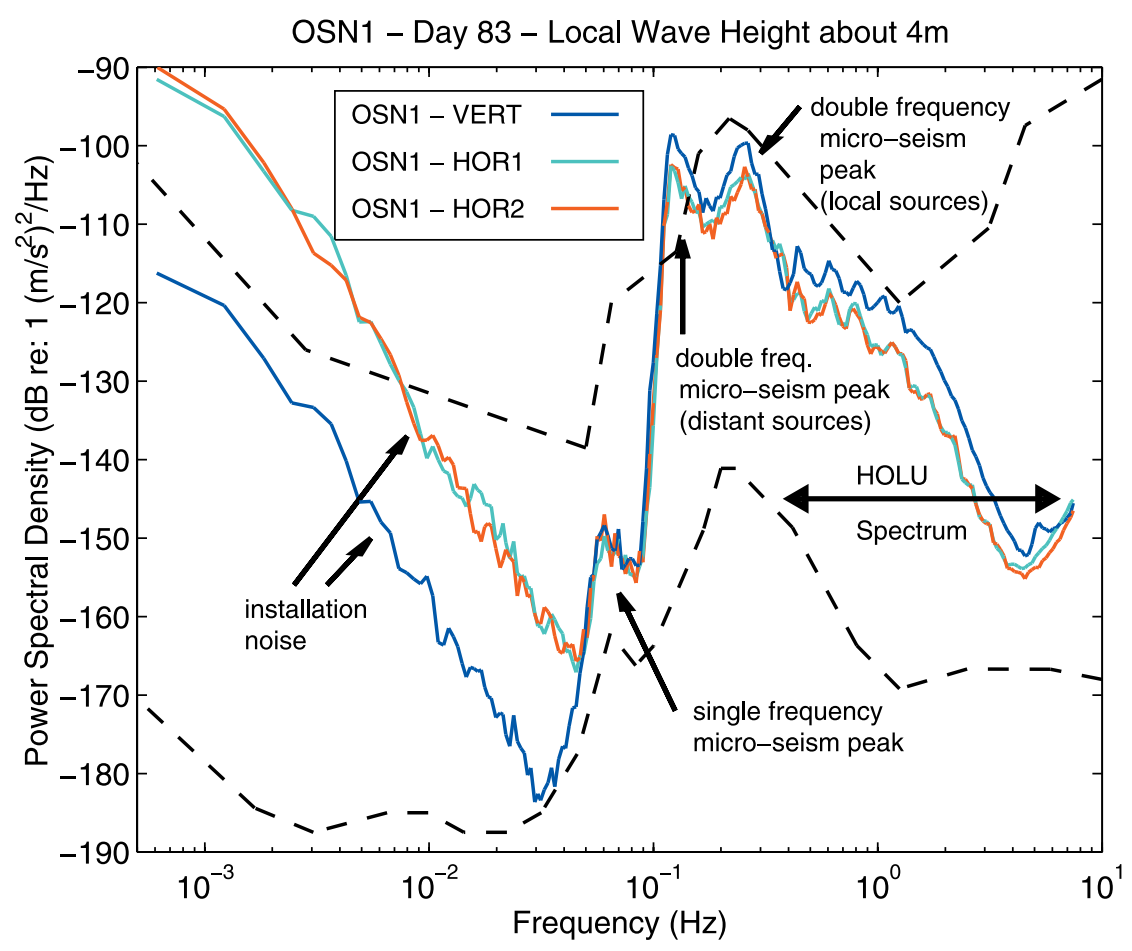

Figure 18. Spectra for the three components of the borehole sensor at OSN-1 are shown for a noisy day with wave heights around $4 \mathrm{~m}$. Noise levels in the microseism band $(0.01-5 \mathrm{~Hz})$ are noisier than for a quiet day in Figure 17, but the horizontal components are still quieter than the vertical. In the noise notch below the microseism peak vertical component levels approach the Peterson low noise model, with levels $80 \mathrm{~dB}$ below the microseism peak. Some common features of broadband spectra are labeled. The HOLU spectrum is associated with local wave heights [McCreery et al., 1993].

(less than $20 \mathrm{~dB}$ ) and are related to sea state. The peak between 0.2 and $0.3 \mathrm{~Hz}$ can be associated with local sea state and wind speed. The peak near $0.1 \mathrm{~Hz}$ begins to appear at lower frequencies and moves to higher frequencies over a few hours (Figure 19). It is attributed to swell from distant storms [Babcock et al., 1994; Bromirski et al., 1999]. The short period band (or HOLU spectrum [McCreery et al., 1993]), $300 \mathrm{mHz}$ to $7.5 \mathrm{~Hz}$, consists of a set of peaks that appear to correspond to shear modes in the seafloor [Butler, 1988; Godin and Chapman, 1999; Nolet and Dorman, 1996; Schreiner et al., 1991; Schreiner and Dorman, 1990; Zeldenrust and Stephen, 2000].

[43] Figure 20 compares vertical and horizontal spectra at the borehole station at OSN-1 with the GSN station at Kipapa. At frequencies from $20 \mathrm{mHz}$ to $7.0 \mathrm{~Hz}$ the borehole sensor is as quiet as or quieter than the island GSN station. Above $2 \mathrm{~Hz}$ the borehole sensor is over $20 \mathrm{~dB}$ quieter than Kipapa on both components. Even though the source of noise at the microseism peak and above (the HOLU spectrum) is associated in some way with gravity waves on the ocean surface [Kibblewhite and Wu, 1991; Longuet-Higgins, 1950; McCreery et al., 1993], the borehole sensor has quieter noise levels than the island station. At the microseism peak itself, where the noise source is postulated to be wave-wave interaction the noise at the borehole sensor is about $6 \mathrm{~dB}$ quieter than the island station. This suggests that Kipapa, on a small island, is more affected by shallow water and coastal processes than deep water sites. For example elastic waves, excited by gravity waves incident on the beach or by the loading of gravity waves in the shallow water surrounding the island, propagate to the seismic station and appear as noise. It is interesting that even at Kipapa the horizontal component is noisier or comparable to the vertical component above the microseism peak, but at the borehole sensor the horizontal is quieter. This is 


\section{OSN1 Vertical}

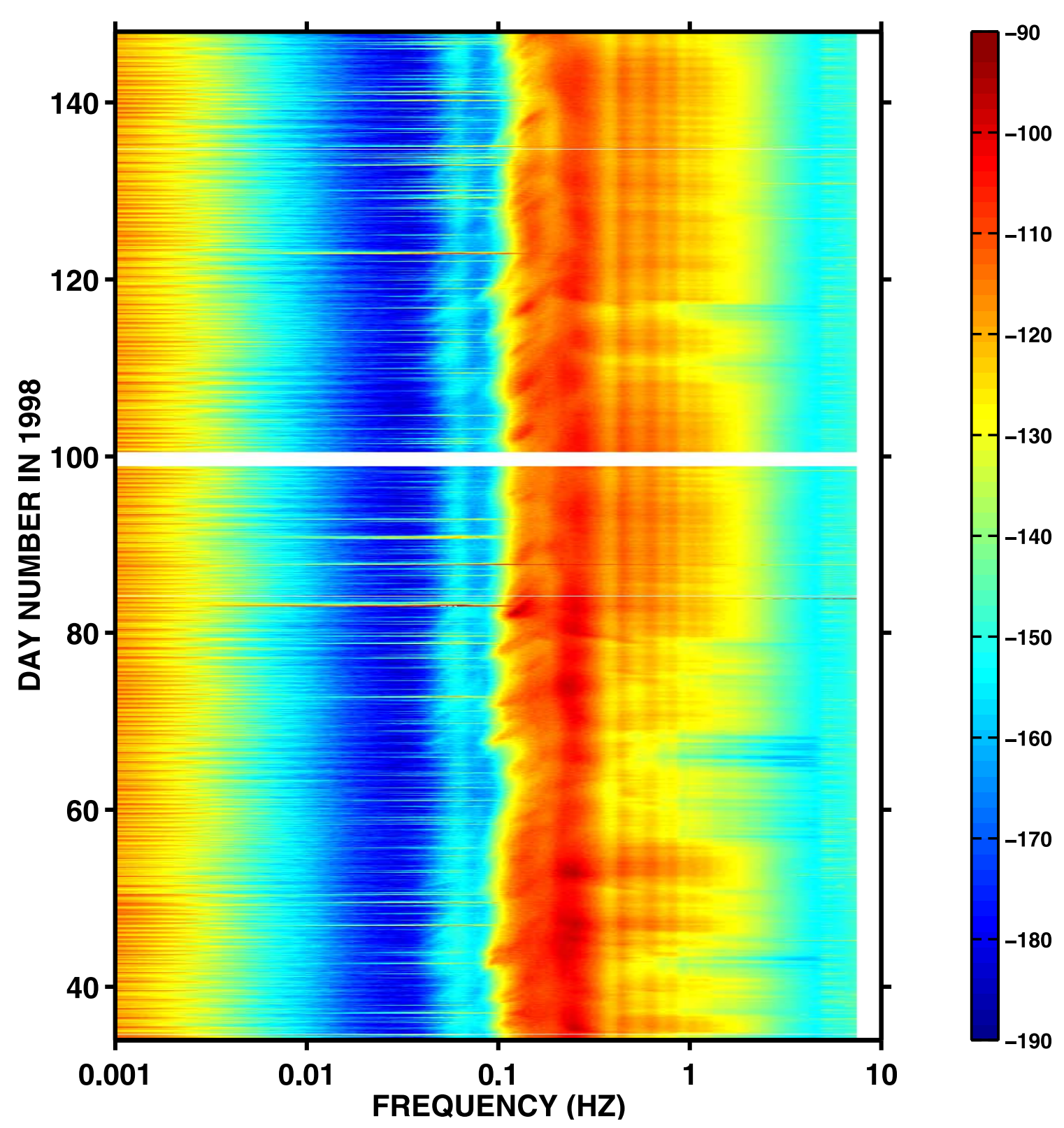

Figure 19. This spectrogram is a compilation of the power spectral density curves (for example, Figures 17 and 18) for the vertical component of the OSN-1 borehole sensor for the duration of the experiment. The vertical bands between about 0.3 and $1 \mathrm{~Hz}$ correspond to shear wave resonances. The evolution of the double frequency microseism peak from distant sources, with lower frequencies arriving several hours before higher frequencies (from just below to just above $0.1 \mathrm{~Hz}$ ) is evident. The variability in the double frequency microseism peak from local sources (between 0.2 and $0.3 \mathrm{~Hz}$ ) is much less dramatic. The thin, red and yellow horizontal bands between 0.01 and $0.1 \mathrm{~Hz}$ correspond to teleseismic earthquake events.

further evidence that the noise excitation and propagation processes at these frequencies are substantially different between island and ocean bottom stations. Certainly for frequencies at the microseism peak and above, ocean bottom seismic observatories can be as quiet as or quieter than island stations, when carefully installed. There are at least two reasons why ocean bottom stations have been 


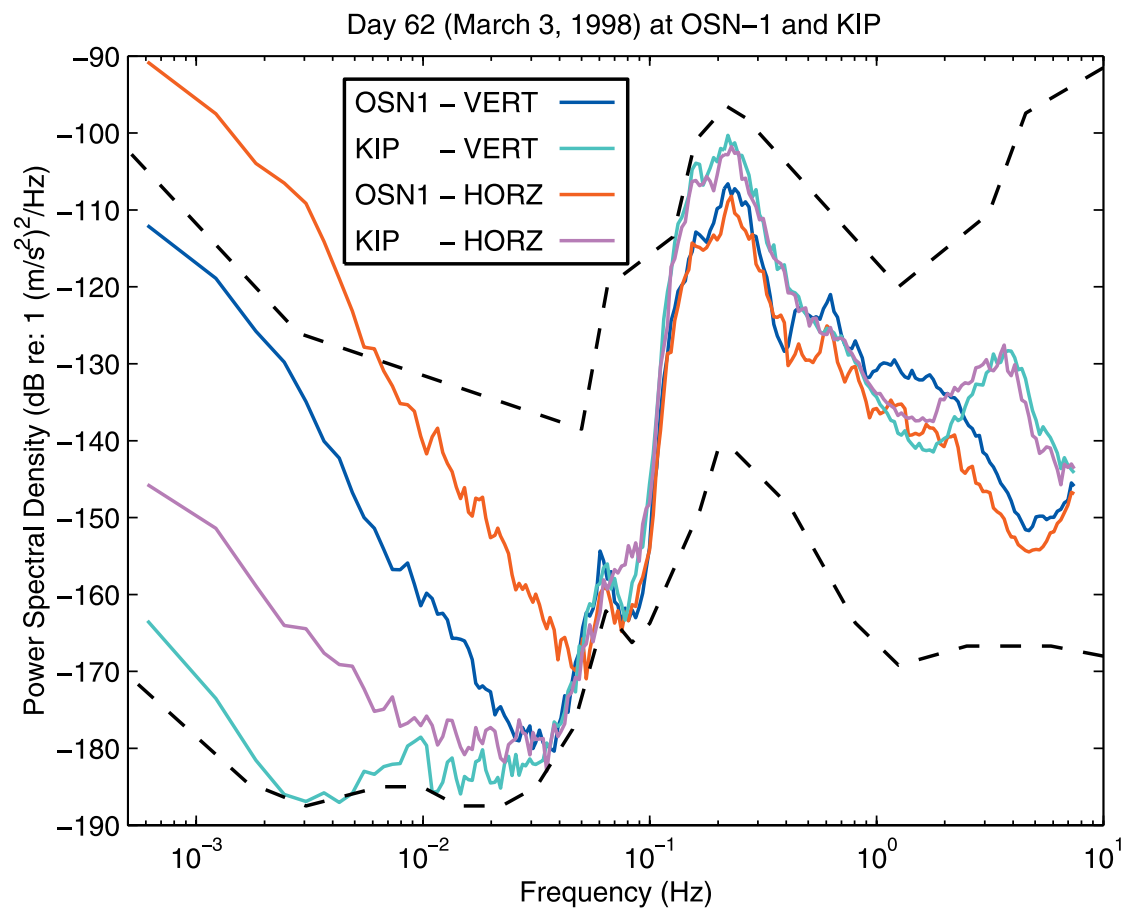

Figure 20. A comparison between the borehole sensor at OSN-1 and the GSN station at Kipapa for the same time interval shows comparable noise levels from 0.03 to $1.5 \mathrm{~Hz}$ on both vertical and horizontal components. The microseism peak is up to $6 \mathrm{~dB}$ quieter in the oceanic basement at OSN-1 than at Kipapa. Below $0.01 \mathrm{~Hz}$ on the horizontal component and below $0.03 \mathrm{~Hz}$ on the vertical component the island station is considerably quieter than the ocean bottom borehole station. The borehole station appears to be subject to installation noise and is not responding to true Earth noise. Except for the horizontal components in the infra-gravity band, the noise levels for the ocean bottom borehole sensor fall within Peterson's high and low noise models (dashed black lines). In the noise notch below the microseism peak vertical component levels in the borehole approach the Peterson low noise model, with levels $80 \mathrm{~dB}$ below the microseism peak at Kipapa.

generally regarded as noisier than island or land stations. One reason which applies at the microseism peak is that ocean bottom sensors are closer to the noise source (the surface gravity waves). This is well established when comparing ocean bottom observations to stations located within the continents, but is less clear for stations near the coast or on small islands as discussed above. A second important reason that applies above the microseism peak is that to date most ocean bottom stations have been installed on low rigidity sediments and are subject to the effects of shear wave resonances (even when the effects of ocean bottom currents exciting instrument noise are not significant). When sensors are placed in boreholes in basement the short period performance of ocean bottom seismic stations approaches that of continental and island stations.
[44] Figures 21 and 22, for vertical and horizontal component data respectively, compare the three broadband seismic configurations deployed on the OSNPE with the Kipapa GSN station and Peterson's land models. Within the microseism and short period bands $(0.1-5 \mathrm{~Hz})$ the background noise levels recorded by the borehole seismograph are substantially less than those of the buried BBOBS. The higher noise levels on the BBOBS are probably a result of scattering of microseism energy by the seafloor and sediment-basement topography into short- wavelength shear modes. This difference in background noise levels means that the detection threshold for short-period body waves is significantly lower for the borehole seismograph than for the BBOBS. Within the microseism and short period bands, the background noise levels of the seafloor and buried BBOBS are similar. 


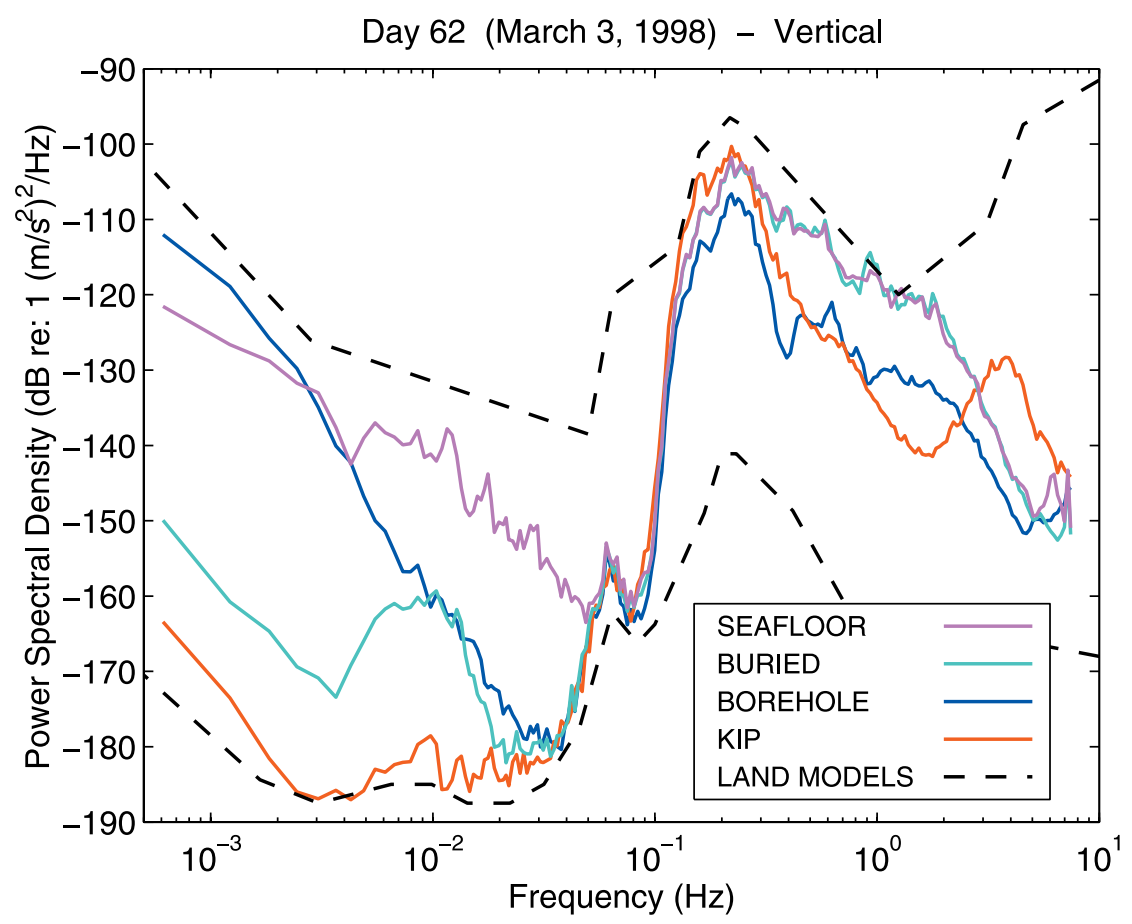

Figure 21. Vertical component spectra for the three broadband seismometer configurations deployed on the OSNPE (seafloor, buried and borehole) and the Kipapa GSN station on Oahu are compared with high and low noise spectral models based on land observations. From $20 \mathrm{mHz}$ to $100 \mathrm{mHz}$ the borehole and buried sensors in the ocean are as quiet as many quiet land sensor.

[45] In the noise notch, at frequencies from 10 to $50 \mathrm{mHz}$, the seafloor BBOBS is $20-40 \mathrm{~dB}$ noisier than the buried BBOBS. The high background noise levels of the seafloor BBOBS appear to be due to ocean-bottom currents pushing on the seismometer generating tilt-induced accelerations or to tilts from ocean turbulence. At frequencies below $10 \mathrm{mHz}$, the noise level of the borehole instrument rises and the buried BBOBS is the quietest instrument. While the origin of this noise on the borehole sensor is not understood, it likely results from the installation of the sonde in a water-filled hole and associated water motion and convection. Although we had intended to install a wire line packer at the bottom of the casing, the packer was sheared off while attempting to recover it for repairs. The experience led us to increase substantially the strength of the weak link at the top of the sonde and to further streamline the seismometer package before deployment. The data collected during this experiment have been made available to the community via the IRIS Data Management System.
[46] Analysis to date has determined the following features in seafloor and sub-seafloor ambient noise [Collins et al., 1999; Collins et al., 1998a; Collins et al., 1998b; Collins et al., 1998c; Stephen et al., 1998a; Stephen et al., 1999b; Stephen et al., 2000; Stephen et al., 2001; Stephen et al., 1998b; Stephen et al., 1998c; Stephen et al., 1998d; Stephen et al., 1998e; Vernon et al., 1998a; Vernon et al., 1998b; Vernon et al., 1999; Vernon et al., 1998c]. Comparing the borehole sensor to the seafloor and buried sensors, all at OSN-1, using spectra computed for the same time intervals shows (Figures 21 and 22): (1) The quietest vertical component sensor in the infra-gravity wave band (0.001$0.01 \mathrm{~Hz}$ ) was on the shallow buried system. (2) The quietest vertical component sensors in the noise notch $(0.01-0.05 \mathrm{~Hz})$ were on the shallow buried and borehole systems. These two systems had comparable levels in this band. (3) For vertical component sensors near the single frequency microseism peak $(0.05-0.1 \mathrm{~Hz})$ all three systems had comparable levels. (4) The quietest vertical component sensor in the microseism and short period bands $(0.1-5 \mathrm{~Hz})$ 


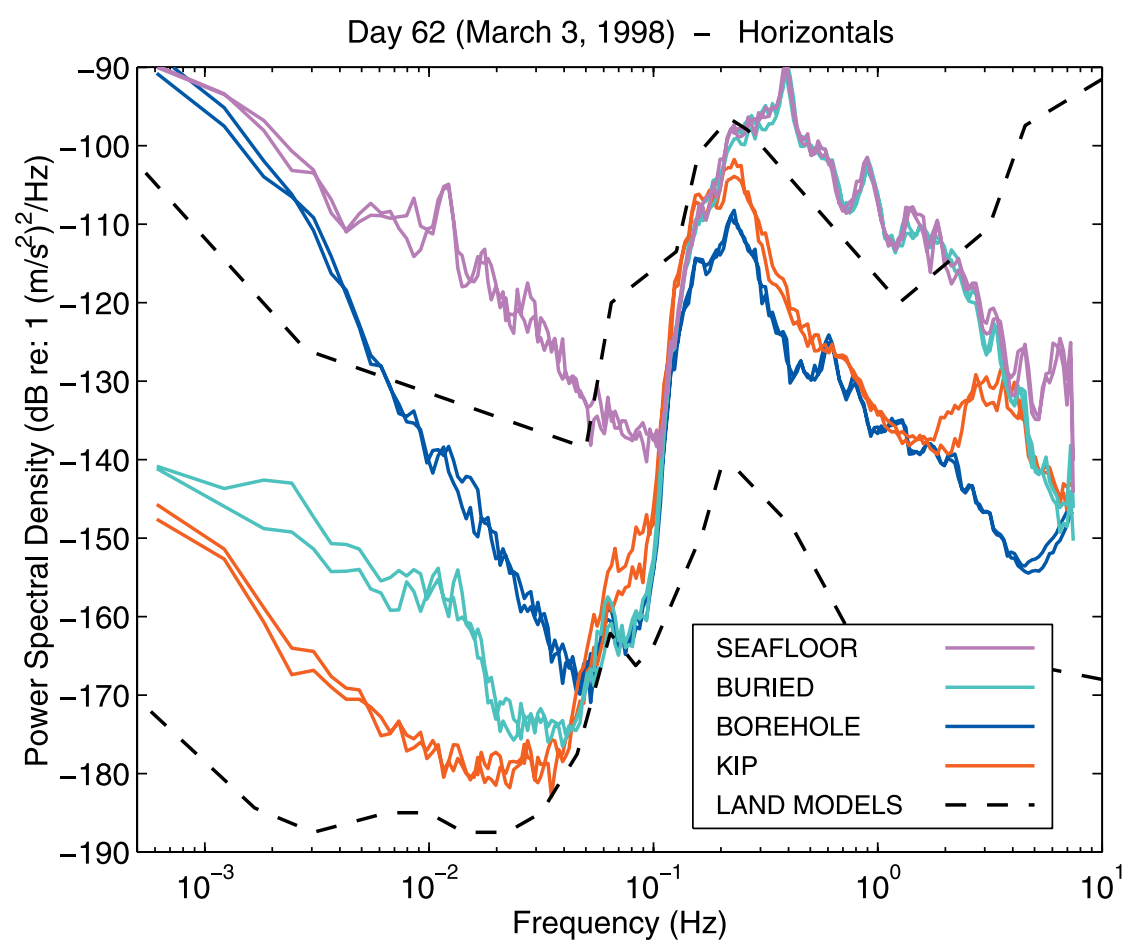

Figure 22. Horizontal component spectra for the three broadband seismometer configurations deployed on the OSNPE (seafloor, buried and borehole) and the Kipapa GSN station on Oahu are compared with high and low noise spectral models based on land observations. The borehole sensor has the quietest oceanic spectrum above $100 \mathrm{mHz}$ and the buried sensor has the quietest oceanic spectrum below $100 \mathrm{mHz}$.

was on the borehole system. (5) The quietest horizontal component sensor in the infra-gravity and noise notch bands $(0.001-0.05 \mathrm{~Hz})$ was on the shallow buried system. (6) The quietest horizontal component sensors near the single frequency microseism peak $(0.05-0.1 \mathrm{~Hz})$ were the shallow buried and borehole systems. (7) The quietest horizontal component sensor in the microseism and short period bands $(0.1-5.0 \mathrm{~Hz})$ was the borehole sensor. Shear modes (shear wave multiples) are a major factor in determining the frequency and magnitude of ambient noise on the horizontal components of any inertial sensors in sediments. Shear wave resonances in sediments at this site have a fundamental frequency of $0.4 \mathrm{~Hz}$ with at least one higher harmonic at about $0.9 \mathrm{~Hz}$ (Figure 22) [Zeldenrust and Stephen, 2000]. This moves the apparent microseism peak for the horizontal components of sensors in the sediment (buried and seafloor) to $0.4 \mathrm{~Hz}$. It also causes $0.4 \mathrm{~Hz}$ resonances in the coda of earthquake events. This resonance is not seen on the borehole sensor clamped just at the sediment/basement contact nor on the vertical component for the sensors in sediment, all of which have a microseism peak around $0.25 \mathrm{~Hz}$. This resonance will depend on the sediment thickness and the shear velocity profile in the sediments [Godin and Chapman, 1999].

[47] Comparing the quietest ocean bottom sensor(s) at OSN-1 to Kipapa, using spectra computed for the same time intervals shows (Figures 21 and 22): (8) The quietest vertical component sensor in the infra-gravity and noise notch bands $(0.001-0.05 \mathrm{~Hz})$ was on Kipapa. For most of this band the quietest ocean bottom sensor was the shallow buried system. On the lower frequency side of the single frequency microseism peak, below $0.05 \mathrm{~Hz}$, the ambient noise levels between the borehole and Kipapa are comparable until the borehole levels rise because of the 'installation noise'. (9) The seafloor, buried, and island stations had comparable vertical component levels in the 
microseism band $(0.05-0.3 \mathrm{~Hz})$. The borehole sensor was as quiet as or quieter than the other OSNPE sensors in this band. At the double frequency microseism peak near $0.2 \mathrm{~Hz}$ the vertical component on the borehole sensor was about $6 \mathrm{~dB}$ quieter than Kipapa. Since previous studies often compare spectra acquired at different times, the similarity of spectra under the same environmental conditions can go unnoticed. (10) For the vertical component in the short period band the OSN-1 borehole sensor was up to $10 \mathrm{~dB}$ quieter than Kipapa from 0.3 to $0.5 \mathrm{~Hz}$ and up to $20 \mathrm{~dB}$ quieter than Kipapa from 2.3 to $7.5 \mathrm{~Hz}$. Kipapa was quieter than the OSN-1 borehole sensor by up to $10 \mathrm{~dB}$ from 0.5 to $2.3 \mathrm{~Hz}$. (11) The quietest horizontal component sensor in the infra-gravity and noise notch bands $(0.001-0.05 \mathrm{~Hz})$ was on Kipapa. For this band the quietest ocean bottom sensor was the shallow buried system. (12) Ambient noise levels on the horizontal components at the OSNPE borehole sensor and Kipapa are within $10 \mathrm{~dB}$ from the instrument noise affect at low frequencies $(0.05 \mathrm{~Hz})$ to $2.3 \mathrm{~Hz}$. The borehole sensor was as quiet as or quieter than the other broadband sensors in this band. For horizontal components at the double frequency microseism peak the borehole sensor was $6 \mathrm{~dB}$ quieter than Kipapa. On the high frequency side of the microseism peak, from 0.4 to $2.3 \mathrm{~Hz}$, the borehole sensor had comparable horizontal levels, within $6 \mathrm{~dB}$, to Kipapa. (13) The quietest horizontal component sensor in the short period band was the OSN-1 borehole sensor. Above about $2.3 \mathrm{~Hz}$ (to at least $5 \mathrm{~Hz}$ ) the borehole sensor was up to $30 \mathrm{~dB}$ quieter than Kipapa.

[48] Considering borehole sensor data alone, using spectra computed for the same time intervals shows (Figures 17 and 18): (14) In the short period band, above about $0.4 \mathrm{~Hz}$, the borehole horizontal components are uniformly quieter by about $6 \mathrm{~dB}$ than the borehole vertical components. This is a remarkable observation and has only been observed once before [Duennebier et al., 1982] in the 45 year history of ocean bottom seismology. Most previous studies on land and the ocean bottom have found that horizontal components are noisier than vertical components. (15) A strong double microseism peak $(0.12$ and $0.25 \mathrm{~Hz})$ was observed on the borehole sensor during high sea states. The traditional single frequency peak, at about $0.06 \mathrm{~Hz}$ [Cessaro, 1994; Cessaro and Chan, 1989] is commonly observed on the borehole sensor. The traditional double frequency peak, caused by local wave-wave interaction, is observed at about $0.25 \mathrm{~Hz}$. The second double frequency peak at $0.12 \mathrm{~Hz}$ is postulated to be caused by wave-wave interaction from distant storms [Babcock et al., 1994]. The frequency is lower than the local peak for two reasons: attenuation in the crust and upper mantle reduces the high frequency content, and the large, low frequency swell from large storms excites lower frequency microseisms.

[49] The power spectral densities displayed in Figures 17, 18, 20, 21 and 22, represent conditions in single $1.82 \mathrm{hr}$ time segments. To address how typical these individual spectra are we plot summaries of the RMS energy levels in particular frequency bands for the whole duration of the pilot experiment in Figure 23. One pair of panels in this figure also shows the minimum level in the noise notch. RMS levels are shown for vertical and horizontal components for all three broadband sensors at OSN-1 and Kipapa. The RMS energy levels were computed by integrating the power spectral densities over the band of interest and the procedure was applied to the whole time series in consecutive $1.82 \mathrm{hr}$ windows, regardless of whether an earthquake event occurred or not. For example the top panels show the RMS energy levels in the band 0.6 to $3 \mathrm{mHz}$. It is clear that, except for isolated peaks Kipapa had the quietest vertical and horizontal energy thoughout the experiment in this band. As mentioned above the borehole sensor had the loudest vertical component noise levels in this band due to installation noise. There is a lot of information in these plots on the time dependence of ambient noise on the various sensors that is beyond the scope of this manuscript. Except for isolated intervals that include earthquake events, the conclusions outlined above based on individual spectra apply throughout the three month acquisition period. 
[50] The broadband data discussed above was acquired on three different types of sensors and it is worth considering how differences in the instrument specifications may affect the results. Figure 24 compares the transfer functions between the input ground velocity (in $\mathrm{nm} / \mathrm{sec}$ ) and the output of the digitizer (in digital counts) of the Teledyne KS54000 (the borehole sensor at OSN-1), the Guralp CMG-3T (the seafloor and buried sensors at OSN-1) and the Streckeisen STS-1 (the vault sensor at Kipapa). All three sensors are flat within $3 \mathrm{~dB}$ in the band from about $0.01 \mathrm{~Hz}$ to over $4 \mathrm{~Hz}$. In this band the maximum difference in transfer function between the three sensors is $4 \mathrm{~dB}$ and although it is important to apply the transfer functions their effects are small. In the infra-gravity band there are considerable differences (up to $20 \mathrm{~dB}$ ) in the transfer functions.

[51] Figure 25 compares representative system noise curves for the Teledyne KS54000 and the Guralp CMG-3T to the New Low Noise Model (NLNM). These curves were taken from manufacturer's specification sheets. Since there is variability in the system noise of sensors of the same type and since the manner in which the sensors are installed in the field can contribute to the overall system noise, these curves should be used as guidelines only in interpreting actual spectra. Although we could not find a system noise curve for the Streckeisen STS-1, it is generally accepted that the Streckeisen STS-1 has system noise below the NLNM between $1 \mathrm{mHz}$ and at least $1 \mathrm{~Hz}$ when connected to a high quality digitizer. As a practical matter all three sensors have system noise below the NLNM in the band from at most $0.04 \mathrm{~Hz}$ to at least $1 \mathrm{~Hz}$. Outside this band observed power spectral density levels represent a maximum for ambient earth noise and one must consider other factors, including system noise, when evaluating the significance of results. For example, in the infra-gravity band the NLNM is considered to represent ambient earth noise because these levels were observed on a number of different vault sensors in different locations world-wide [Peterson, 1993]. As another example, at frequencies above $1 \mathrm{~Hz}$, the observed spectral levels sometimes correlate with tides. Although this may indicate installation noise (fluid flow past the sensor), it is unlikely to indicate system noise. It could also indicate, however, true ambient earth noise since currents over a rough seafloor, which are themselves tidally dependent, may excite vibrations. A detailed discussion of these issues is beyond the scope of this paper.

\subsection{Earthquake Signals}

[52] Ambient noise behavior is, of course, not the whole story. The objective of an ocean seismic network is to observe earthquakes. If the amplitude of the earthquake signals decreases as much as the ambient noise level then not much is accomplished. It is the signal-to-noise ratio that determines detectability and the quality and eventual usefulness of the earthquake signal.

[53] A thorough analysis of signal-to-noise and threshold magnitudes for the OSNPE has been presented by Sutherland et al. (submitted manuscript, 2003). The threshold magnitudes do mirror the ambient noise results presented above. Above the microseism peak where short period $\mathrm{P}$ and $\mathrm{S}$ waves are observed the borehole sensor, which has much quieter ambient noise, also detected more events than the seafloor or shallow-buried sensors. Below the microseism peak, where the buried sensor had the lowest observed ambient noise levels, the buried sensor also detected the most long-period S and surface waves. Overall the ocean bottom borehole broadband seismic installation provided comparable threshold magnitudes to near-by island stations.

[54] Some examples of earthquake events, from Collins et al. [1998c], are included here to indicate the quality of the data as observed on various sensors in different frequency bands. The locations of a sample of fifty-five teleseismic earthquakes that were observed on the broadband systems are shown in Figure 26. These range from a $4.5 \mathrm{mb}$ event at $44^{\circ}$ epicentral distance (2/14/98 2:15:03) to the $7.9 \mathrm{Mw}$ Balleny Islands earthquake at $91^{\circ}$ epicentral distance (3/25/98 3:12:26). The short period $(2-5 \mathrm{~Hz})$ performance is demonstrated by the $4.7 \mathrm{mb}$ Fiji earthquake at an epicentral distance of $41^{\circ}$ (Figure 27). All three broadband ocean 

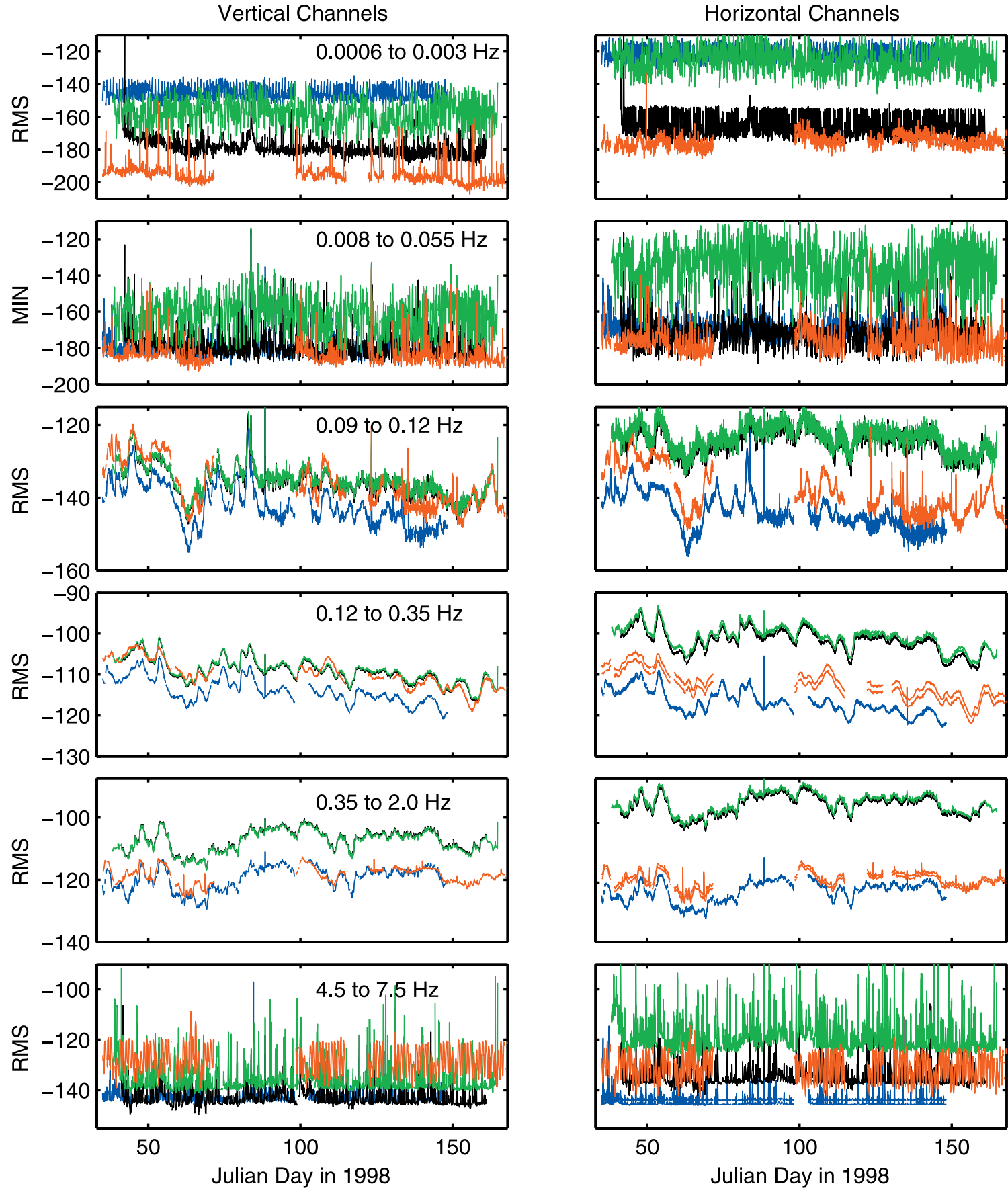

Borehole

KIP

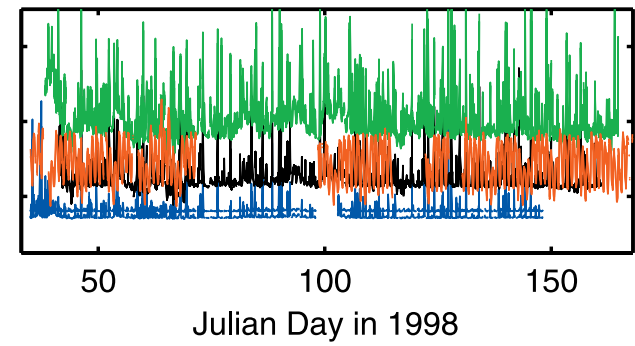

Seafloor

Buried

Figure 23. In order to compare the three sensor types at OSN-1 with Kipapa for the whole three month deployment we reduce the power spectral density computed on a 1.82hour window (for example Figures 20 to 22) to a single number for six significant frequency bands. Plots on the left show data for the vertical component and plots on the right show data for the two horizontal components. Plots with the ordinate labeled "RMS" display the RMS energy in $\mathrm{dB}$ re: $1 \mathrm{~m} / \mathrm{s}^{2}$ in the frequency bands indicated. The plot labeled "MIN" displays the minimum power spectral density in $\mathrm{dB}$ re: $1\left(\mathrm{~m} / \mathrm{s}^{2}\right)^{2} / \mathrm{Hz}$ in the noise notch. The relative levels and their variability between sensor types and components in each band can readily be observed for the whole experiment. The results are discussed in the text. 


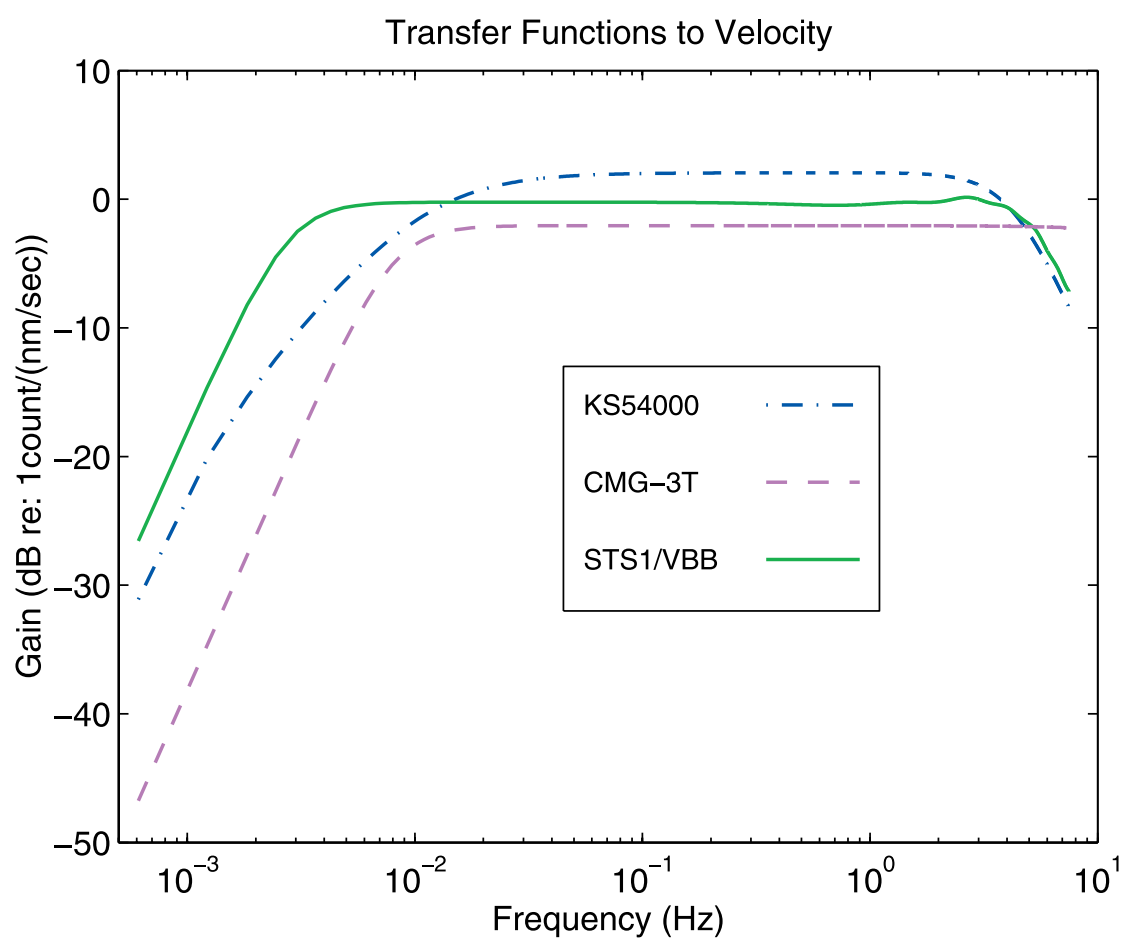

Figure 24. The transfer functions between digital counts and ground motion as obtained from the IRIS Data Management Center are shown for the three broadband sensors for which data is discussed in this paper (the Teledyne KS54000, the Guralp GMG-3T and the Streckeisen STS-1). All three have a response which is flat to velocity within the passband from near $0.01 \mathrm{~Hz}$ to over $4 \mathrm{~Hz}$. These curves can be useful in interpreting observed power spectral densities. The shapes of the curves shown in Figures 17, 18, 20, 21, and 22 in the passband are not related to differences in the transfer functions of the sensors.

bottom systems recorded pickable $\mathrm{P}$ wave arrivals on the vertical components but the event was not clearly observed on broadband stations on the neighboring islands. This is one the quietest events observed on the OSNPE.

[55] The 7.9 Mw Balleny Islands earthquake was the largest event recorded on the OSNPE (Figure 28). For this event the long period $(0.01-0.07 \mathrm{~Hz})$ three component data on the borehole and shallow buried sensors is comparable but the noise on the horizontal channels of the seafloor sensor is readily evident. A similar figure for the smaller 7.0 Mw Sumatra earthquake (Figure 29) shows that the horizontal components of the seafloor instrument are essentially unusable.

[56] Figure 30 compares the seafloor and shallow buried broadband sensors with the conventional (1 Hz geophone) sensor in the intermediate period band $(0.03-0.07 \mathrm{~Hz})$ for the $6.6 \mathrm{Mw}$ New Britain earthquake. As observed on the MELT experiment
[Wilcock et al., 1999] conventional sensors yield good signal-to-noise ratios for surface waves in this band.

\section{Discussion of Ocean Bottom Ambient Noise}

[57] The Ocean Seismic Network Pilot Experiment was special because it compared three different broadband seismic installations (seafloor, shallow buried and borehole) at the same ocean bottom location for a duration of three months. All three sensors responded to the same environmental conditions and the same earthquake events. No experiment before or since has done this. In comparing OSNPE results to results from other experiments it is necessary to sort out the overlap in parameter space. Some of the experiments that were carried out prior to the OSNPE are reviewed in section 2 . Since the OSNPE there have been broadband borehole, shallow buried and seafloor observations 


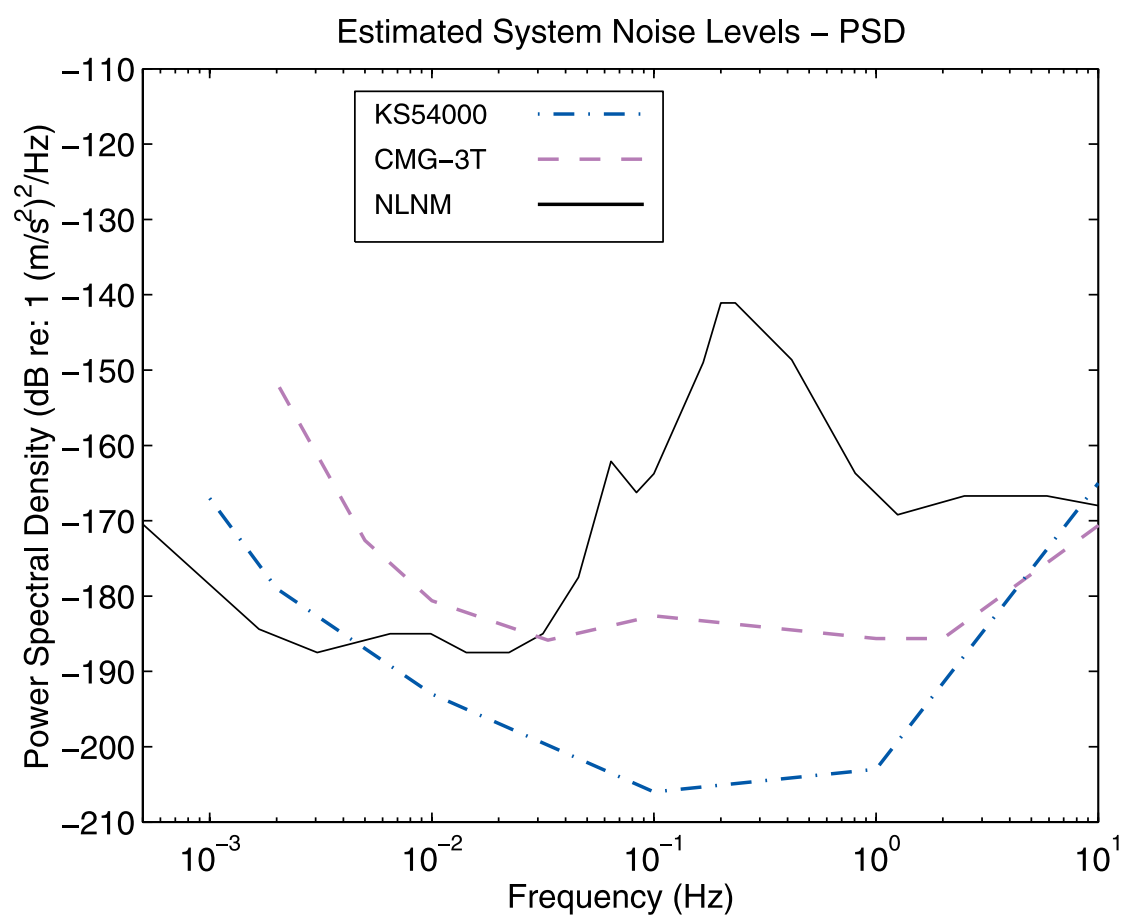

Figure 25. Representative system noise curves (converted to equivalent ground acceleration at the input) for the two sensors used in the OSN Pilot Experiment (the Teledyne KS54000 [Geotech Instruments, 1999] and the Guralp CMG-3T [Guralp Systems Limited, 1996]) are compared to the New Low Noise Model (NLNM) [Peterson, 1993]. These curves were taken from manufacturer's specification sheets. Since there is variability in the system noise of sensors of the same type and since the manner in which the sensors are installed in the field can contribute to the overall system noise, these curves should be used as guidelines only in interpreting actual spectra. The power spectral density curves can be converted to equivalent peak earth acceleration by integrating over $1 / 3$ octave bands and multiplying by 1.253 [Peterson, 1993]. It is generally accepted that the Streckeisen STS-1 has system noise below the NLNM between $1 \mathrm{mHz}$ and at least $1 \mathrm{~Hz}$ when connected to a high quality digitizer [Peterson, 1993; Wielandt, 1991; Wielandt and Steim, 1986; Wielandt and Streckeisen, 1982].

with much longer durations but the systems have not been co-located and in some cases only preliminary results have been published.

[58] How has the OSN Pilot Experiment changed our view of seafloor ambient noise? Collins et al. [2001] reported on the principal results of the experiment. The primary result was A-1) that ocean bottom stations, properly installed, could be comparable in quality to quiet land and island stations. The ambient noise results are distinctly different for frequencies in the bands 1 to $100 \mathrm{mHz}$ (below the microseism peak) and $100 \mathrm{mHz}$ to $7.5 \mathrm{~Hz}$ (above the microseism peak). Above the microseism peak: A-2) data quality was best for a borehole seismometer in basement, A-3) the seafloor and buried broadband instruments (as well as the seafloor VLF instrument) had comparable noise levels indicating that the observed levels were real environmental noise and could not be attributed to instrument resonances, system noise or strumming of the instruments by bottom currents, A-4) peaks in the spectra above the microseism peak indicated the presence of Stoneley/Scholte modes in the sediments which have reduced amplitudes on the borehole sensor in basement, A-5) the seafloor and buried broadband instruments had vertical component noise levels 10 to $15 \mathrm{~dB}$ higher than the borehole instrument and about $5 \mathrm{~dB}$ higher than conventional OBS's at the MELT experiment [Wilcock et al., 1999], A-6) all three broadband sensors showed similar variations in vertical component noise with wind speed, and A-7) the seafloor and buried broadband instruments had horizontal component noise levels about $30 \mathrm{~dB}$ higher than the borehole instrument. Below the 


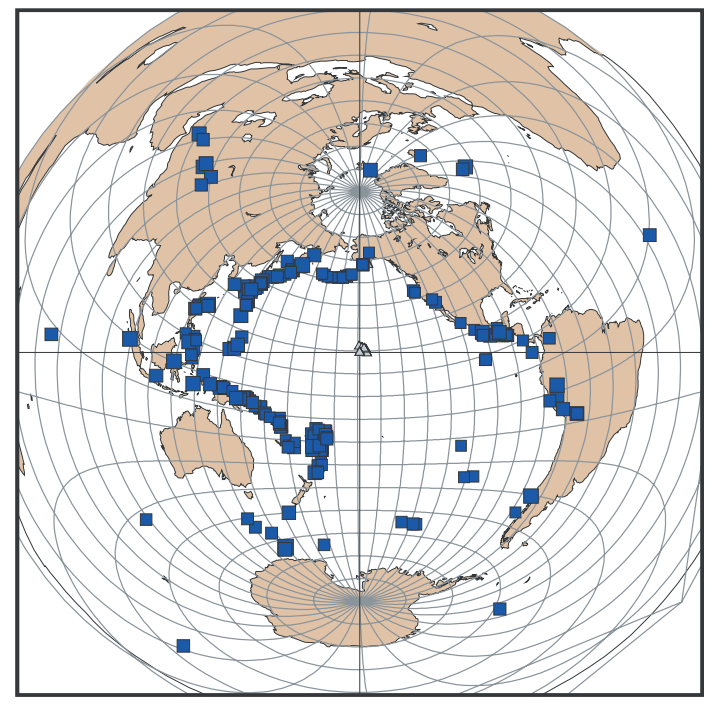

Figure 26. The locations of fifty-five of the earthquakes that were initially identified on the OSNPE broadband systems between February 7 and May 27, 1998 are shown. The events shown range from a $4.5 \mathrm{mb}$ event at $44^{\circ}$ epicentral distance (2/14/98 2:15:03) to the $7.9 \mathrm{Mw}(5.8 \mathrm{mb})$ Balleny Islands earthquake at $91^{\circ}$ epicentral distance (3/25/98 3:12:26). A more thorough analysis of 30 short-period $\mathrm{P}$ wave events, 77 long period $\mathrm{S}$-wave events and 165 long period surface wave events is presented in Sutherland et al. (submitted manuscript, 2003). Symbols are scaled by magnitude. The OSN-1 Site is located at the center of the cross-hairs.

microseism peak: B-8) data quality was best for a buried seismometer, B-9) the buried sensor was sufficiently quiet to resolve the "compliance peak" near $0.01 \mathrm{~Hz}$ [Crawford et al., 1991], and B-10) the observed noise in the band 20 to $50 \mathrm{mHz}$ on the seafloor broadband sensor could be associated with tilting caused by tidally induced bottom currents. For earthquake events: E-11) signal levels in the bands 5 to $7.4 \mathrm{mHz}, 20-50 \mathrm{mHz}, 67$ to $125 \mathrm{mHz}$, and 0.1 to $3.0 \mathrm{~Hz}$ are similar on all three components between the buried and borehole installations so that detectability and signal-to-noise ratio reflect the variations in ambient noise in each case, and E-12) for surface waves in the 20 to $50 \mathrm{mHz}$ band, which are useful in constraining upper mantle structure, buried or borehole broadband sensors have better resolution than seafloor sensors, particularly for the horizontal components.

[59] In addition to providing more background material on why we carried out the OSNPE in the first place, to providing more information on the equipment and field operations and to reviewing the data and conclusions, this paper identifies two new results. First above the microseism peak, ambient noise levels on the horizontal components of the borehole sensor are quieter than on the vertical component. We attribute this to the dramatic reduction in shear wave resonances on entering the high rigidity basement. Because of the low shear velocity of the sediments the ray paths corresponding to the resonances are near vertical and the shear particle motions are predominantly horizontal. Also because of the low rigidity in the sediments, for the same energy level the amplitude of the shear waves will be much greater in the sediments than in basement. The vertical component particle motion can be primarily associated with compressional waves. For the same energy, compressional wave amplitudes are less sensitive to the dramatic changes in shear modulus than shear waves. Secondly the second double frequency microseism peak near $100 \mathrm{mHz}$, related to distant sources, evolves over two to four days with the lower frequencies arriving first. Figure 19, for example, is a nice display of the evolution of the microseism peaks with time as originally discussed by Babcock et al. [1994].

[60] How do the OSNPE results compare to the other broadband borehole experiments and pilot tests? Duennebier et al. [1982] were the first to recognize the sudden reduction in the amplitude of the modes on entering basement, but their experiment obtained noise spectra only at frequencies above the microseism peak. Many subsequent studies, including Butler [1988], Schreiner and Dorman [1990], Dorman et al. [1991], Webb [1998], Nolet and Dorman [1996] and Godin and Chapman [1999] have discussed the importance of shear modes, Stoneley modes, or shear wave multiples in sediments. The OSNPE, with simultaneously recording seafloor, shallow buried, and borehole broadband systems observed shear mode effects over a broad range of earthquake events and environmental conditions. The reduction in short period horizontal component ambient noise on entering basement at OSN-1, where the sensor was clamped in basement only within $10 \mathrm{~m}$ of the sedimentbasement contact, is about $5-10 \mathrm{~dB}$ more dramatic 


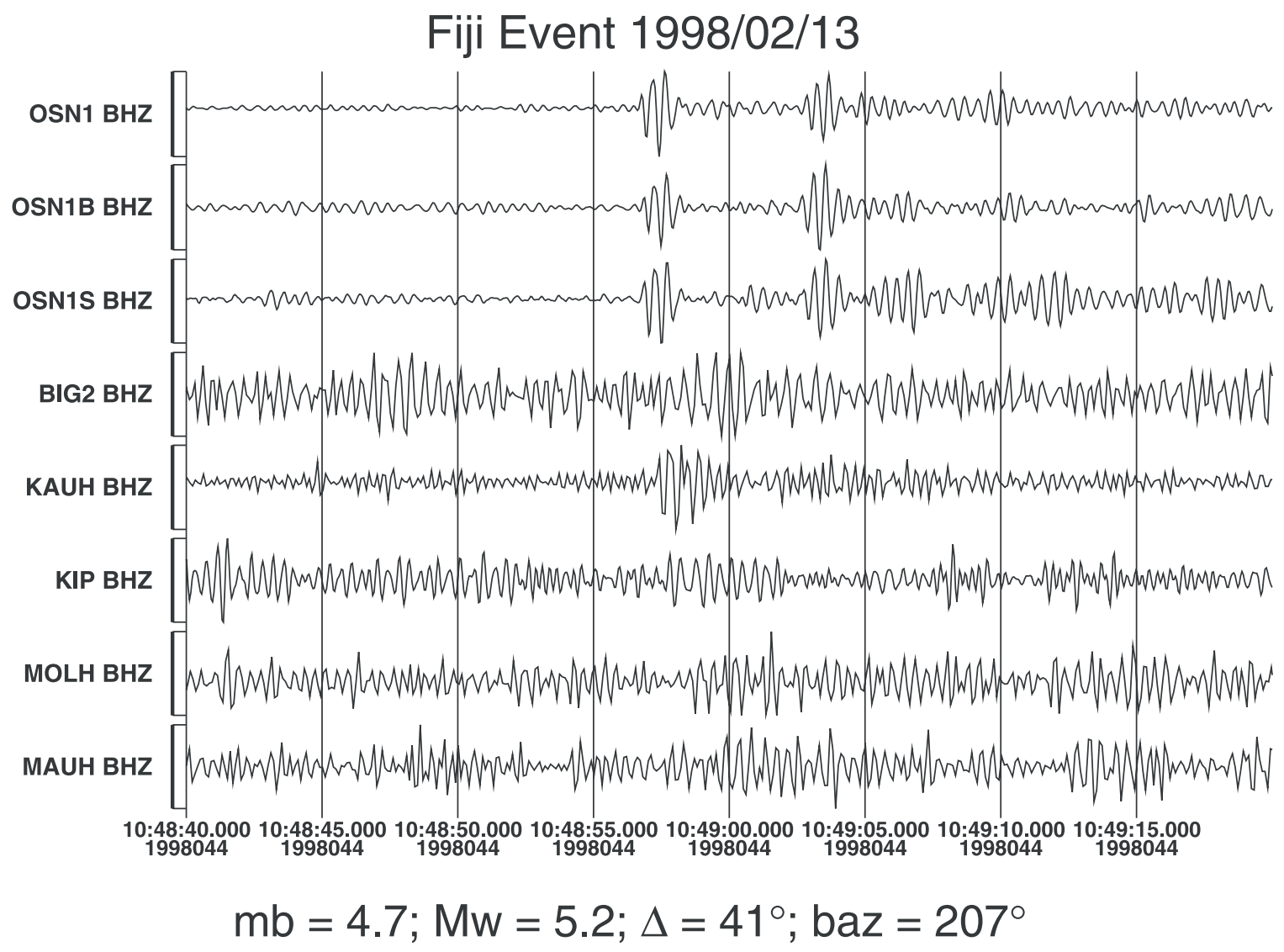

Figure 27. Short period, vertical component body wave seismograms from the $4.7 \mathrm{mb}$ Fiji earthquake (13 February, 1998) are shown for the three OSNPE broadband seismographs and three PELENET broadband seismographs. Despite very high microseism noise levels observed on the buried and seafloor stations, compared to the borehole station, all three stations record pickable $\mathrm{P}$ wave arrivals. This is one of smallest teleseismic earthquakes observed on the OSNPE. The data have been bandpass filtered 2-5 Hz. Station names OSN1, OSN1B and OSN1S refer to the borehole, shallow buried and seafloor instruments deployed on the OSNPE respectively. Station names BIG2, KAUH, MAUH, and MOLH refer to the temporary PELENET stations on Hawaii (Big Island), Kauai, Maui and Molokai, respectively.

than the reduction in VLF ambient noise with depth in the upper $100 \mathrm{~m}$ of sediments alone, as observed by Bradley et al. [1997]. Resonance peaks are still observed in the HOLU spectrum even for the borehole sensor at OSN-1 and so there is still room for further reduction in ambient noise by installing the sensor even deeper into basement. The depth dependence of shear mode amplitudes, however, is not monotonic and depending on the shear wave velocity and attenuation profile at a given site deeper sensors may observe higher amplitudes for some modes and higher ambient noise levels in some parts of the HOLU spectrum [Dorman et al., 1991; Nolet and Dorman, 1996]. This could explain the apparently anomalous observation of Carter et al. [1984] mentioned above in the background section. Note that this does not explain the observations of Montagner et al. [1994a] because their noise study focused on frequencies below the microseism peak where the wavelengths are too long for the shear resonance mechanism to apply.

[61] At low frequencies, the OSNPE borehole ambient noise data are contaminated by installation noise. Other studies, however, have shown that borehole seismic installations can be much quieter than seafloor sensors and as quiet as buried sensors at frequencies below $100 \mathrm{mHz}$ [Shinohara et al., 2002; Suyehiro et al., 2002]. Suyehiro et al. noted that the horizontal ambient noise at $10 \mathrm{mHz}$ was $60 \mathrm{~dB}$ quieter in the borehole at WP-2 than on the seafloor and that 
Balleny Islands Event 03/25/98

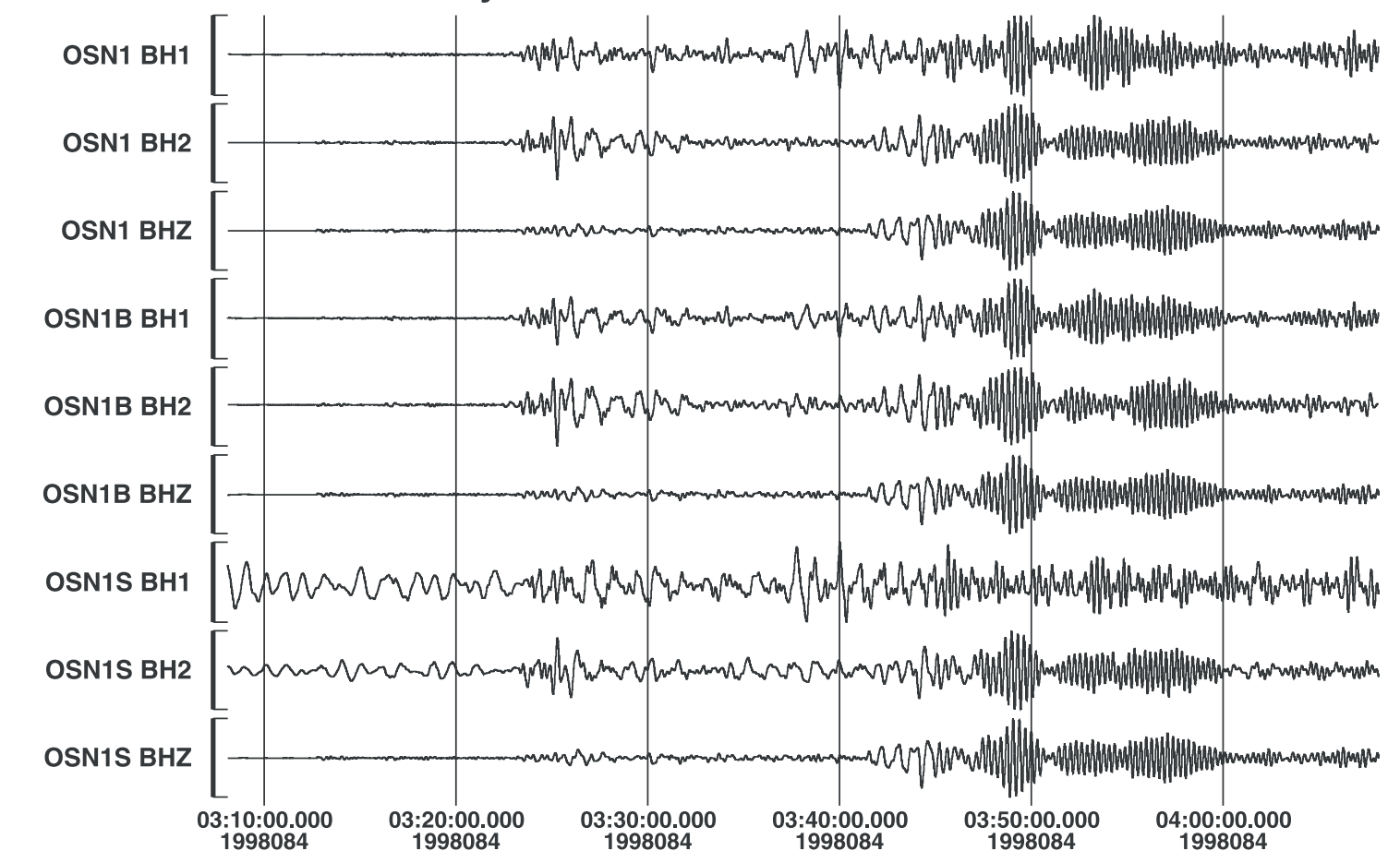

$$
\mathrm{Mw}=8.0 ; \mathrm{Ms}=7.7 ; \mathrm{mb}=5.8 ; \text { depth }=0 \mathrm{~km} ; \Delta=91.4^{\circ} ; \mathrm{baz}=201^{\circ}
$$

Figure 28. Long period, three component body and surface wave seismograms from the 7.9 Mw Balleny Islands earthquake (25 March 1998) are shown for the three OSNPE broadband sensors. Note the high noise levels on the horizontal components of the seafloor BBOBS. This is the largest event observed during the OSNPE. The data have been bandpass filtered $0.01-0.07 \mathrm{~Hz}$. BHZ refers to a broadband vertical component channel and $\mathrm{BH} 1$ and $\mathrm{BH} 2$ refer to the broadband horizontal component channels.

the effects of seafloor tidal currents were not observed on the borehole data. Although seafloor seismometers typically detect teleseismic events with magnitudes greater than 6.0, the borehole sensor at WP-2 was detecting events with magnitudes less than 5.0. In the band $3-10 \mathrm{mHz}$ the horizontal component borehole spectra at WP-2 were quieter than the horizontal component buried spectra at OSN-1 [Shinohara et al., 2002]. Also in the same band the vertical component borehole spectra at the Mid-Atlantic Ridge site [Montagner et al., 1994a] were comparable to the vertical component buried spectra at OSN-1. Although these borehole data were not acquired at the same time and place as the buried data, there is evidence to suggest that in the absence of installation noise borehole sensors should have comparable noise levels to buried sensors at low frequencies. A theoretical analysis of tilts due to loading by surface gravity waves predicts that the borehole sensor in basement should be even quieter than a collocated buried sensor in sediment [Araki, 1999], although this hypothesis has not yet been confirmed by observations.

[62] Some of the complicating factors in the OFMSISMOBS test in 1992 [Montagner et al., 1994a] were discussed in the background section above. The Nyquist frequency in this experiment was $5 \mathrm{~Hz}$ and the published spectra display the band from about a milliHertz to $1 \mathrm{~Hz}$. An interesting observation is that the microseism peak (in acceleration units) on OFM-SISMOBS is just below $1 \mathrm{~Hz}$, instead of near the band 0.16 to $0.33 \mathrm{~Hz}$ observed on land stations. The whole displayed spectra addresses only frequencies below the microseism peak and the interesting issues involving shear wave resonances in the HOLU spectrum above 


\section{Sumatra Event 1998/04/01}

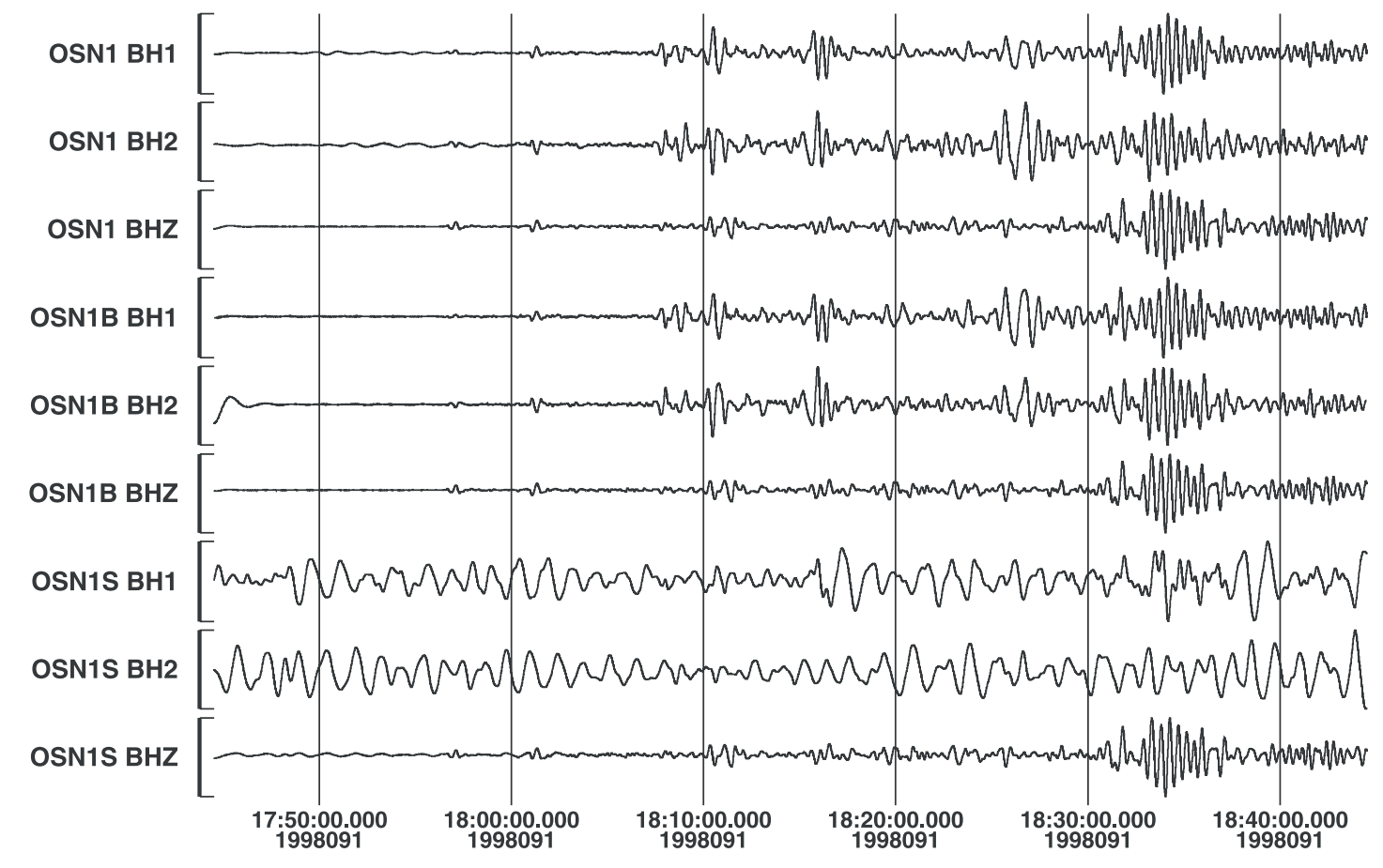

$\mathrm{Mw}=7.0 ; \mathrm{mb}=6.2 ; \mathrm{Ms}=6.9 ;$ Depth $=42 \mathrm{~km} ; \Delta=102^{\circ} ; \mathrm{baz}=273^{\circ}$

Figure 29. Long period, three component body and surface wave seismograms from the $7.0 \mathrm{Mw}$ Sumatra earthquake (1 April 1998) are shown for three OSNPE broadband sensors. Note the unusable horizontal components of the seafloor BBOBS (OSN1S). The horizontal data recorded by the borehole seismograph (OSN1) are noisier than the equivalent data recorded by the shallow buried seismograph (OSN1B). The data have been bandpass filtered 0.01-0.07 Hz. Station and channel identifiers are the same as in Figures 27 and 28.

the microseism peak are not addressed in the 1994 paper. Although the higher microseism peak has been observed on other experiments [Bradley et al., 1997, for example], it was not observed on the OSNPE or at many other sites [Romanowicz et al., 1998; Webb, 1998, for example] and does not appear to be a ubiquitous feature of ocean bottom ambient noise. It would be interesting to have long time series of ambient noise in the North Atlantic, to observe the time dependence of the higher frequency microseism peak and its dependence on environmental conditions.

[63] Since the OSNPE a shallow-buried broadband seismometer has been installed at the Hawaii-2 Observatory (H2O) [Duennebier et al., 2002]. Ambient noise spectra show strong resonances even though the sediment thickness is only $30 \mathrm{~m}$ [e.g., Stephen et al., 2003]. A broadband borehole seismic installation at this site is planned for 2004 and it will be interesting to compare the shallow buried and borehole response at $\mathrm{H} 2 \mathrm{O}$ with other sites.

[64] Webb [1998] is an excellent review of the state-of-the-art in ocean bottom ambient noise prior to the Ocean Seismic Network Pilot Experiment in the spring of 1998. A convenient way to summarize the OSNPE results is to outline where they agree and disagree with Webb [1998]. Analysis of the OSNPE data indicates the following points:

[65] 1. Webb [1998, p. 107] states

High-frequency noise propagates poorly from ocean to land, resulting in a quieter noise spectrum near $1 \mathrm{~Hz}$ at island stations than adjacent seafloor sites. A comparison of island sites with historical bounds from seafloor noise spectra in the microseism band concluded that short-period noise at seafloor sites could be comparable to noise levels at island sites [Hedlin and Orcutt, 1989], but such quiet conditions are probably rare in the Pacific. The most significant difference between most seafloor sites and continental sites is the very high noise level near $1 \mathrm{~Hz}$. The OSN-1 site is $20-30 \mathrm{~dB}$ noisier at $1 \mathrm{~Hz}$ than the island site and $40 \mathrm{~dB}$ noisier than the quietest land sites [Peterson, 1993]. 


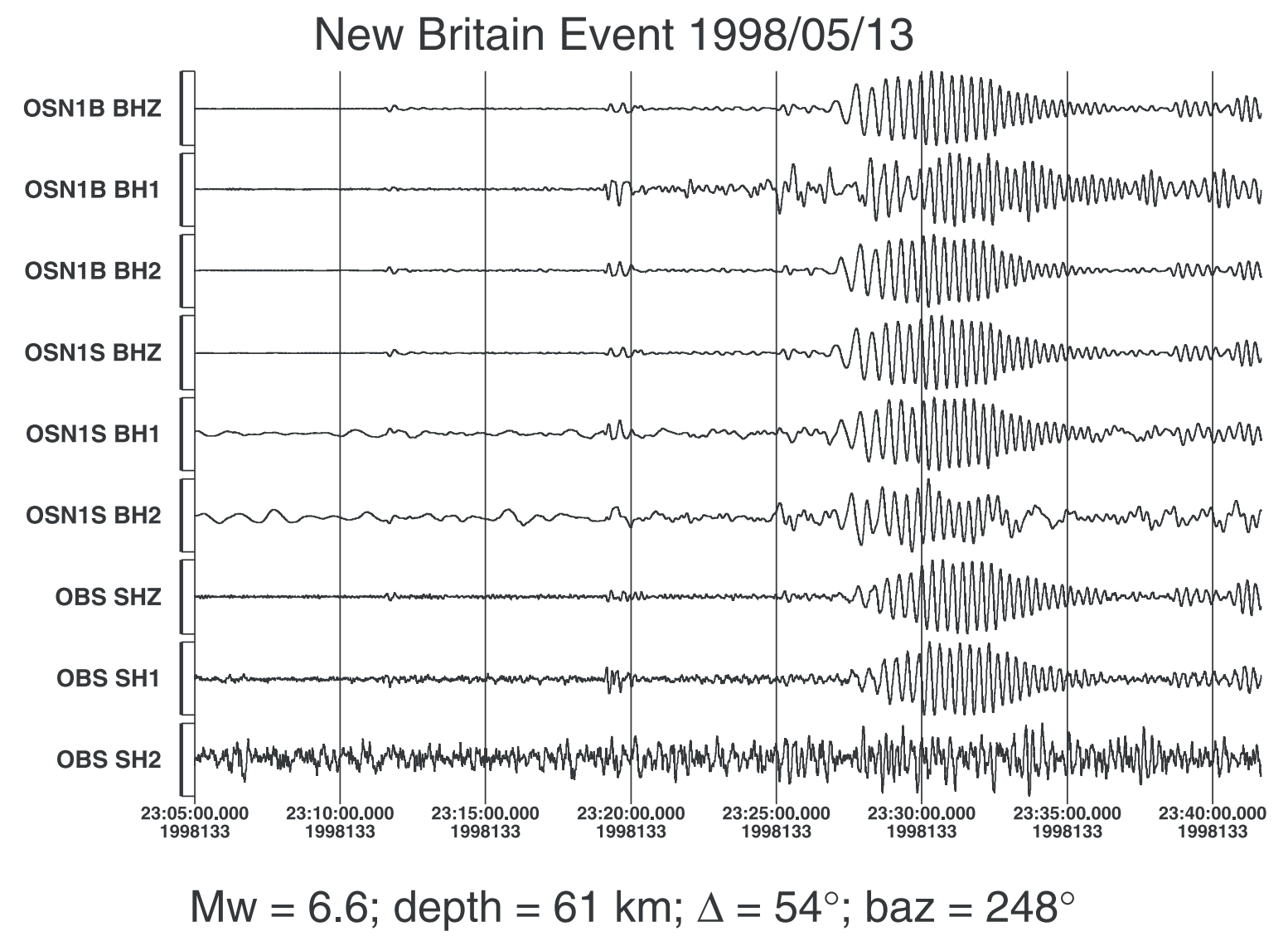

Figure 30. Intermediate period, three component body and surface wave seismograms from the 6.6Mw New Britain earthquake (13 May 1998) are shown for the shallow buried BBOBS (OSN1B), the seafloor BBOBS (OSN1S) and a conventional short period OBS (OBS). The OBS data are considerably noisier than the two BBOBS. Channel OBS$\mathrm{H} 2$ is oriented perpendicular to the great circle arc between source and receiver and does not record the Rayleigh wave just prior to 23:20 nor the Love wave just after 23:25. The data have been bandpass filtered 0.01-0.07 Hz. Channel identifiers are the same as in Figure 28.

[66] Webb's comments are probably based on seafloor or shallow buried instruments, but the borehole sensor at OSN-1 gives dramatically different results. (The semantics here can be confusing. Does "seafloor site" refer only to instruments literally "on the seafloor", as the seafloor BBOBS at OSN-1, or does "seafloor site" refer to any installation, including shallow buried or borehole sensors? The author may intend the former, but the reader may interpret the latter. In this paper we use "seafloor" to refer to sensors or processes at the water-sediment or waterbasement interface and "ocean bottom" to refer to sensors or processes at or below the seafloor.) The conclusions may also be based on short observation intervals and on comparisons between data from ocean bottom and island stations acquired at different times. (1) Spectra from the OSNPE show that the
OSN-1 borehole and KIP vertical components at $1 \mathrm{~Hz}$ are within $3 \mathrm{~dB}$ and that the OSN-1 horizontals are comparable to or quieter than KIP (Figures 20, 21 and 22). (2) Peterson's high and low noise models differ by about $50 \mathrm{~dB}$ at $1 \mathrm{~Hz}$. Although the OSN-1 borehole spectra are 30-35 dB noisier than the low noise model, OSN-1 borehole levels at $1 \mathrm{~Hz}$ are still $15-20 \mathrm{~dB}$ quieter than Peterson's high noise curve for land sites. (3) From 2.5 to $5.0 \mathrm{~Hz}$ for vertical channels and from 1.5 to $5.0 \mathrm{~Hz}$ for horizontal channels the OSN-1 borehole sensor is quieter by up to $25 \mathrm{~dB}$ than the island station, KIP, presumably because of cultural noise on Oahu. (4) At the microseism peak near $0.25 \mathrm{~Hz}$ the OSN-1 borehole levels are rarely noisier than Peterson's high noise model and on quiet days can be over $10 \mathrm{~dB}$ quieter. (5) The seafloor and 
island stations had comparable horizontal and vertical component levels near the microseism peak $(0.05-1.0 \mathrm{~Hz})$. At the microseism peak $(0.25 \mathrm{~Hz})$ the borehole sensor can actually be up to $6 \mathrm{~dB}$ quieter. The OSN-1 observations are similar to the OSS-IV observations in the band $2-40 \mathrm{~Hz}$ acquired in a similar geological environment in the northwest-Pacific [Duennebier et al., 1987a].

[67] 2. The quieter short period noise translates into better detection levels for earthquakes. Webb [1998, pp. 106, 121] states

Ocean floor instruments may not significantly improve capabilities for detection and localization of remote (teleseismic) earthquakes in many areas because of high noise levels. The word "teleseismic" can be used to describe any arrival from distances greater than $10^{\circ}$, but in this paper it will refer primarily to arrivals at ranges greater than $30^{\circ}$. It is now possible with continental arrays to detect all earthquakes with $\mathrm{m}_{\mathrm{b}}>4.5$ almost anywhere in the world [Bolt, 1976].

The improvements in signal-to-noise ratio for sensors at shallow depths in boreholes ( $>10 \mathrm{mbsf})$ should lower detection thresholds for short-period body waves from $7.5 \mathrm{~m}_{\mathrm{b}}$ expected for noisy seafloor sites (saturated microseism spectrum) to about $6.5 \mathrm{~m}_{\mathrm{b}}$ (Figure 7). Detection limits for quiet seafloor noise conditions are expected to fall below $5.5 \mathrm{~m}_{\mathrm{b}}$.

[68] On the OSN-1 borehole sensor, we see short period teleseismic arrivals in the band $2.0-5.0 \mathrm{~Hz}$, for a $4.7 \mathrm{~m}_{\mathrm{b}}$ earthquake at $41^{\circ}$ epicentral distance (Figure 27). A more thorough analysis of the detectability of earthquakes observed on the OSNPE is given by Sutherland et al. (submitted manuscript, 2003).

\section{[69] 3. Webb [1998, pp. 121, 122] states}

The results from the several borehole experiments to date are consistent. Vertical noise levels are lower within the basement rocks $(10-15 \mathrm{~dB}$ at $1 \mathrm{~Hz}$, increasing to $20 \mathrm{~dB}$ at about $5 \mathrm{~Hz})$. Signal levels are also smaller (because of changing impedance), so that the resulting improvement in signal-to-noise ratio is near zero at $0.2 \mathrm{~Hz}$ and increases to more than $10 \mathrm{~dB}$ at a few hertz.

Borehole installation can provide a small but significant improvement in signal to noise for short-period arrivals compared with seafloor installations. For short-period measurements there do not appear to be significant advantages to drilling much deeper or significant differences between installation in rock rather than sediments.

[70] Analysis of earthquake signals at OSN-1 shows comparable signal levels on the shallow buried and borehole sensors for both vertical and horizontal components in the ULF and VLF bands. There is no indication to date of the reduction in signal amplitude caused by the impedance contrast between sediments and basement (Figures 27 to 29). The borehole sonde was clamped within $10 \mathrm{~m}$ of this contact and the complete effect of the borehole impedance may not be felt at such a shallow penetration. Short period signal-to-noise ratios do appear to be significantly better on the borehole sensor (Sutherland et al., submitted manuscript, 2003).

\section{Conclusions}

[71] Certainly for frequencies at the microseism peak and above, ocean bottom seismic observatories can be as quiet as or quieter than island stations, when carefully installed. Although at the microseism peak ocean bottom sensors are noisier than stations within the continents (because they are closer to the surface gravity waves which are the noise source in this band), there is a second important reason why ocean bottom sensors are generally regarded as "noisy." At frequencies above the microseism peak to date most ocean bottom stations have been installed on low rigidity sediments and are subject to the effects of shear wave resonances (even when the effects of ocean bottom currents exciting instrument noise are not significant). By placing sensors in boreholes in basement the effects of these resonances are reduced, and ocean bottom ambient noise levels above the microseism peak are not as "noisy" as commonly assumed. Burial in the soft mud appears to be adequate to obtain excellent noise levels for frequencies below the microseism peak. There are hypotheses that borehole sensors may give improved performance in this band as well, and it will be interesting to see the results of other broadband borehole seismic experiments where installation noise is not an issue. Properly installed ocean bottom seismic installations can be as good as most land stations and in many frequency bands can be among the quietest stations in the world.

\section{Acknowledgments}

[72] The Ocean Seismic Network Pilot Experiment was a collaborative effort involving about twenty scientists, engineers and technicians from Woods Hole Oceanographic Institution and Scripps Institution of Oceanography. We would like to especially thank G. L. Austin, S. T. Bolmer, C. D. Chadwell, D. Jabson, P. Jonke, R. G. Goldsborough, M. R. Gould, C. R. Hollinshead, D. E. Koelsch, D. G. Offield, S. G. Rosenblad, and D. F. Willoughby for their contributions ashore and at sea. 
The deployment cruise was carried out on the R/V Thomas G. Thompson, run by the University of Washington, and under the command of Captain G. Gomes. The recovery cruise was carried out on the R/V Melville, run by Scripps Institution of Oceanography and under the command of Captain E. Buck. C. Wolfe graciously provided data from the PELENET network on the Hawaiian Islands for comparisons with the OSNPE results. Hole 843B (OSN-1) was drilled on ODP Leg 136 specifically for the borehole seismic installation. ODP is sponsored by the U.S. National Science Foundation (NSF) and participating countries under management by Joint Oceanographic Institutions (JOI), Inc. We would like to thank A. Dziewonski, R. H. Wilkens, J. V. Firth and the scientific and engineering party, Captain E. G. Oonk and the SEDCO marine officers and crew, K. D. Horne and the SEDCO drilling personnel, and the ODP technical and logistics personnel on Leg 136. This work was sponsored by the National Science Foundation (NSF Grant Numbers: OCE-9522114, OCE9523541 and OCE-9819439) with additional support from Incorporated Research Institutions for Seismology (IRIS), Joint Oceanographic Institutions, Inc. (JOI Contract No: 12-94), Scripps Institution of Oceanography, a Mellon Grant from Woods Hole Oceanographic Institution, and the Earthquake Research Institute at the University of Tokyo (Visiting Professorship for RAS). Woods Hole Oceanographic Institution Contribution Number: 10935.

\section{References}

Adair, R. G., J. A. Orcutt, and T. H. Jordan, Analysis of ambient seismic noise recorded by downhole and ocean-bottom seismometers on Deep Sea Drilling Project Leg 78B, Initial Rep. Deep Sea Drill. Project, 78, 767-781, 1984.

Araki, E., Geophysical nature of broadband seismic signals in deep oceans, Ph.D., thesis, Univ. of Tokyo, Tokyo, 1999.

Auld, B., G. Latham, A. A. Nowroozi, and L. Seeber, Seismicity off the coast of northern California determined from ocean bottom seismic measurements, Bull. Seismol. Soc. Am., 59, 2001-2015, 1969.

Babcock, J. M., B. A. Kirkendall, and J. A. Orcutt, Relationships between ocean bottom noise and the environment, Bull. Seismol. Soc. Am., 84, 1991-2007, 1994.

Barash, T. W., C. G. Doll Jr., J. A. Collins, G. H. Sutton, and S. C. Solomon, Quantitative evaluation of a passively leveled ocean bottom seismometer, Mar. Geophys. Res., 16, 347-363, 1994.

Barstow, N., G. H. Sutton, and J. A. Carter, Particle motion and pressure relationships of ocean bottom noise: $3900 \mathrm{~m}$ depth; 0.003-5 Hz, Geophys. Res. Lett., 10, 1185-1188, 1989.

Becker, K., E. E. Davis, F. N. Spiess, C. de Moustier, and the DRIFT 03 Technical Party, Wireline CORKs deployed for long term hydrogeological investigations in holes 504B and 896A, Costa Rica Rift, and the first in-situ video collected from within upper oceanic crust, Eos Trans. AGU, 82(47), Fall Meet. Suppl., Abstract OS218-0454, 2001.

Bolt, B. A., Nuclear Explosions and Earthquakes: The Parted Veil, W. H. Freeman, New York, 1976.
Bradley, C. R., Very low frequency seismo-acoustic noise below the sea floor $(0.2-10 \mathrm{~Hz})$, Ph.D., thesis, Mass. Inst. of Technol. and Woods Hole Oceanogr. Inst., Woods Hole, Mass., 1994.

Bradley, C. R., R. A. Stephen, L. M. Dorman, and J. A. Orcutt, Very low frequency $(0.2-10.0 \mathrm{~Hz})$ seismoacoustic noise below the seafloor, J. Geophys. Res., 102, 11,703-11,718, 1997.

Bradner, H., J. G. Dodds, and R. E. Foulks, Investigation of microseism sources with ocean bottom seismometers, Geophysics, 30, 511-526, 1965.

Bromirski, P. D., Vibrations from the "Perfect Storm", Geochem. Geophys. Geosyst., 2, Paper number 2000GC000119, 2001.

Bromirski, P. D., and F. K. Duennebier, The near-coastal microseism spectrum: Spatial and temporal wave climate relationships, J. Geophys. Res., 107(B8), 2166, doi:10.1029/ 2001JB000265, 2002.

Bromirski, P. D., R. E. Flick, and N. Graham, Ocean wave height determined from inland seismometer data: Implications for investigating wave climate changes in the NE Pacific, J. Geophys. Res., 104, 20,753-20,766, 1999.

Butler, R., Shear wave properties of marine sediments derived from cepstral analysis of background noise, Geophys. Res. Lett., 8, 836-839, 1988.

Butler, R., Proposed station locations and rationale for the OSN component of GSN, in Broadband Seismology in the Oceans: Towards a Five-Year Plan, edited by G. M. Purdy and J. A. Orcutt, pp. 20-25, Ocean Seismic Network, Joint Oceanogr. Inst., Washington, D. C., 1995.

Carson, B., K. Becker, G. M. Purdy, R. Wilkens, J. Gieskes, and J. Hildebrand, BOREHOLE: A plan to advance postdrilling, sub-seafloor science, Joint Oceanogr. Inst./U.S. Sci. Advis. Comm., Washington, D. C., 1996.

Carter, J. A., F. K. Duennebier, and D. M. Hussong, A comparison between a downhole seismometer and a seismometer on the ocean floor, Bull. Seismol. Soc. of Am., 74, 763-772, 1984.

Cessaro, R. K., Sources of primary and secondary microseisms, Bull. Seismol. Soc. Am., 84, 142-148, 1994.

Cessaro, R. K., and W. W. Chan, Wide-angle triangulation array study of simultaneous primary microseism sources, J. Geophys. Res., 94, 15,555-15,563, 1989.

Collins, J. A., F. L. Vernon, J. A. Orcutt, K. R. Peal, R. A. Stephen, J. A. Hildebrand, and F. N. Spiess, Performance of the portable broadband ocean-bottom seismographs (BBOBS) during the Ocean Seismic Network Pilot Experiment, paper presented at Long-Term Monitoring of the Mid-Atlantic Ridge: MOMAR, InterRidge Office, Univ. Pierre et Marie Curie, Lisbon, Portugal, Oct. 1998a.

Collins, J. A., F. L. Vernon, J. A. Orcutt, K. R. Peal, F. B. Wooding, J. A. Hildebrand, F. N. Spiess, and R. A. Stephen, Performance of the portable broadband ocean-bottom seismograph (BBOBS) during the Ocean Seismic Network Pilot Experiment, January-June, 1998, paper presented at the Tenth Annual IRIS Workshop, Inc. Res. Inst. for Seismol., Santa Cruz, Calif., July 1998b. 
Collins, J. A., F. L. Vernon, J. A. Orcutt, R. A. Stephen, K. R. Peal, J. A. Hildebrand, and F. N. Spiess, Relative performance of the borehole, surficially-buried, and seafloor broadband seismographs on the Ocean Seismic Network Pilot Experiment: Frequency-domain results, Eos Trans. AGU, 79(46), Fall Meet. Suppl., F661, 1998c.

Collins, J. A., K. R. Peal, R. A. Stephen, F. L. Vernon, J. A. Orcutt, J. A. Hildebrand, and F. N. Spiess, Lessons from the ocean seismic network pilot experiment, J. Acoust. Soc. Am., 105, 1168, 1999.

Collins, J. A., F. L. Vernon, J. A. Orcutt, R. A. Stephen, K. R. Peal, F. B. Wooding, F. N. Spiess, and J. A. Hildebrand, Broadband seismology in the oceans: Lessons from the ocean seismic network pilot experiment, Geophys. Res. Lett., 28, 49-52, 2001.

Collins, J. A., F. L. Vernon, J. A. Orcutt, and R. A. Stephen, Upper mantle structure beneath the Hawaiian swell: Constraints from the ocean seismic network pilot experiment, Geophys. Res. Lett., 29(11), 1522, doi:10.1029/ 2001GL013302, 2002.

Cox, C., T. Deaton, and S. Webb, A deep-sea differential pressure gauge, J. Atmos. Oceanic. Technol., 1, 237-246, 1984.

Crawford, W. C., S. C. Webb, and J. A. Hildebrand, Seafloor compliance observed by long-period pressure and displacement measurements, J. Geophys. Res., 96, 16,151-16,160, 1991.

de Moustier, C., F. N. Spiess, D. Jabson, P. Jonke, G. Austin, and R. Zimmerman, Deep-sea borehole reentry with fiber optic wireline technology, 2000 International Symposium on Underwater Technology, pp. 379-384, Inst. of Electr. and Electr. Eng., New York, 2000.

Dorman, L. M., A. E. Schreiner, and L. D. Bibee, The effects of shear structure on seafloor noise, in Shear Waves in Marine Sediments, edited by J. Hovem, R. Stoll, and M. Richardson, pp. 239-245, Kluwer Acad., Norwell, Mass., 1991.

Dougherty, M. E., and R. A. Stephen, Seismic energy partitioning and scattering in laterally heterogeneous ocean crust, J. Pure Appl. Geophys., 128, 195-229, 1988.

Dozorov, T. A., and S. Soloviev, Spectra of ocean-bottom seismic noise in the $0.01-10 \mathrm{~Hz}$ range, Geophys. J. Int., 106, 113-121, 1992.

Duennebier, F. K., G. Blackinton, and G. H. Sutton, Currentgenerated noise recorded on ocean bottom seismometers, Mar. Geophys. Res., 5, 109-115, 1981.

Duennebier, F., et al., OSS IV: The results of the downhole seismometer experiment, DSDP leg 88 (abstract), Eos Trans. $A G U, 63,1025,1982$.

Duennebier, F. K., C. S. McCreery, D. Harris, R. K. Cessaro, C. Fisher, and P. Anderson, OSS IV: Noise levels, signal-tonoise ratios, and noise sources, Initial Rep. Deep Sea Drill. Project, 88, 89-103, 1987a.

Duennebier, F. K., et al., Site 581: Downhole seismometer experiment in the Northwest Pacific, Initial Rep. Deep Sea Drill. Project, 88, 9-36, 1987b.

Duennebier, F. K., et al., Geoacoustic ocean noise from 0.1 to $100 \mathrm{~Hz}$ recorded off Oregon: The ULF/VLF experiment, in Oceans '91, Inst. of Electr. and Electr. Eng., New York, 1991.
Duennebier, J. K., and G. H. Sutton, Fidelity of ocean bottom seismic observations, Mar. Geophys. Res., 17, 535-555, 1995.

Duennebier, F. K., D. W. Harris, J. Jolly, J. Babinec, D. Copson, and K. Stiffel, The Hawaii-2 observatory seismic system, IEEE J. Oceanic Eng., 27, 212-217, 2002.

Dziewonski, A., R. Wilkens, J. Firth, and Shipboard Scientific Party, Background and objectives of the ocean seismographic network, and Leg 136 drilling results, Proc. Ocean Drill. Program Initial Rep., 136, 3-8, 1992.

Forsyth, D., S. Sacks, and A. Tréhu, JOI/IRIS Ocean Seismic Network - U.S. Pilot Experiment Task Force Meeting, Joint Oceanographic Inst., Inc., Washington, D. C., 1991.

Geotech Instruments, Broadband Borehole Seismometer System, Dallas, Tex., 1999.

Godin, O. A., and D. M. F. Chapman, Shear-speed gradients and ocean seismo-acoustic noise resonances, J. Acoust. Soc. Am., 106, 2367-2382, 1999.

Guralp Systems Limited, Guralp CMG-3T Broadband Seismometer, Reading, U.K., 1996.

Hedlin, M. A., and J. A. Orcutt, A comparative study of island, seafloor, and subseafloor ambient noise levels, Bull. Seismol. Soc. Am., 79, 172-179, 1989.

IRIS, The IRIS Proposal: A Science Facility for Studying the Dynamics of the Solid Earth, IRIS Consortium, Arlington, Va., 1995.

Jordan, T. H., H. W. Menard, J. H. Natland, and J. A. Orcutt, Introduction: Objectives and results of DSDP Leg 91 and the Ngendie seismic experiment, and explanatory notes for volume 91, Initial Rep. Deep Sea Drill. Project, 91, 185203, 1987.

Kanazawa, T., K. Suyehiro, N. Hirata, and M. Shinohara, Performance of the ocean broadband downhole seismometer at site 794, Proc. Ocean Drill. Project Sci. Results, 127/128, 1157-1171, 1992.

Kasahara, J., H. Utada, T. Sato, and H. Kinoshita, Submarine cable OBS using a retired submarine telecommunication cable: GeO-TOC Program, Phys. Earth Planet. Int., 108, 113-128, 1998.

Kibblewhite, A. C., and C. Y. Wu, The theoretical description of wave-wave interactions as a noise source in the ocean, J. Acoust. Soc. Am., 89, 2241-2252, 1991.

Laske, G., J. P. Morgan, and J. A. Orcutt, First results from Hawaiian SWELL pilot experiment, Geophys. Res. Lett., 26, 3397-3400, 1999.

Latham, G. V., and A. A. Nowroozi, Waves, weather, and ocean bottom microseisms, J. Geophys. Res., 73, 39453956, 1968.

Latham, G. V., and G. H. Sutton, Seismic measurements on the ocean floor: 1. Bermuda area, J. Geophys. Res., 71, 25452573, 1966.

Lay, T., and T. C. Wallace, Modern Global Seismology, Academic, San Diego, Calif., 1995.

Legrand, J., A. Echardour, H. Floc'h, L. Floury, J. Gieskes, F. Harmegnies, G. Loaec, J.-P. Pozzi, Y. Raer, and R. Stephen, Campagne FARE: Wireline reentry of DSDP Hole 396B using the NADIA system, Trans. AGU, 70(30), 729, 1989. 
Longuet-Higgins, M. S., A theory of the origin of microseisms, Philos. Trans. R. Soc. London, Ser. A, 243, 1-35, 1950.

McCreery, C. S., F. K. Duennebier, and G. H. Sutton, Correlation of deep ocean noise $(0.4$ to $30 \mathrm{~Hz})$ with wind, and the Holu Spectrum - A worldwide constant, J. Acoust. Soc. Am., 93, 2639-2648, 1993.

Montagner, J.-P., and Y. Lancelot, Multidisciplinary observatories on the deep seafloor, Inst. Natl. of Sci. of Univ./Cent. Natl. Rech. Sci., Marseille, 1995.

Montagner, J. P., et al., The French Pilot Experiment OFMSISMOBS: First scientific results on noise level and event detection, Phys. Earth Planet. Int., 84, 321-336, 1994a.

Montagner, J. P., B. Romanowicz, and J. F. Karczewski, A first step toward an oceanic geophysical observatory, Trans. $A G U, 75(13), 150,1994 \mathrm{~b}$.

Morin, R. H., A. E. Hess, and K. Becker, In-situ measurements of fluid flow in DSDP holes 395A and 534A: Results from the DIANAUT program, Geophys. Res. Lett., 19, 509-512, 1992.

Nolet, G., and L. M. Dorman, Waveform analysis of Scholte modes in ocean sediment layers, Geophys. J. Int., 125, 385396, 1996.

Orcutt, J., A. Harding, and A. Levander, The effects of seafloor roughness on reverberation: finite difference and Kirchhoff simulations, in Ocean Reverberation, edited by D. D. Ellis, J. R. Preston, and H. G. Urban, pp. 221-226, Kluwer Acad., Norwell, Mass., 1993a.

Orcutt, J. A., C. S. Cox, A. C. Kibblewhite, W. A. Kuperman, and H. Schmidt, Observations and causes of ocean and seafloor noise at ultra-low and very-low frequencies, in Natural Physical Sources of Underwater Sound, edited by B. R. Kerman, pp. 203-232, Kluwer Acad., Norwell, Mass., 1993b.

Peterson, J., Observations and modeling of seismic background noise, U.S. Geol. Surv. Open File Rep., 93-322, 91 pp., 1993.

Purdy, G. M., and A. M. Dziewonski, Proceedings of a workshop on broad-band downhole seismometers in the deep ocean, Joint Oceanogr. Inst., Sci. Advis. Comm., Washington, D. C., 1988.

Purdy, G. M., and J. A. Orcutt, Broadband seismology in the oceans - Towards a five-year plan, Ocean Seismic Net./Joint Oceanogr. Inst., Washington, D. C., 1995.

Romanowicz, B., et al., MOISE: A pilot experiment towards long term sea-floor geophysical observatories, Earth Planets Space, 50, 927-937, 1998.

Schreiner, A. E., L. M. Dorman, and L. D. Bibee, Shear wave velocity structure from interface waves at two deep water sites in the Pacific Ocean, in Shear Waves in Marine Sediments, edited by J. M. Hovem et al., pp. 231-238, Kluwer Acad., Norwell, Mass., 1991.

Schreiner, M. A., and L. M. Dorman, Coherence lengths of seafloor noise: Effect of ocean bottom structure, J. Acoust. Soc. Am., 88, 1503-1514, 1990.

Shinohara, M., T. Kanazawa, E. Araki, K. Suyehiro, H. Shiobara, T. Yamada, K. Nakahigashi, H. Mikada, and Y. Fukao, Ambient Seismic Noise Levels of the Seafloor Borehole Broadband Seismic Observatories in the Northwest- ern Pacific, Eos Trans. AGU, 83(47), Fall Meet. Suppl., Abstract S71A-1052, 2002.

Spiess, F. N., D. E. Boegeman, and C. Lowenstein, First ocean-research-ship-supported fly-in reentry to a deep ocean drill hole, Mar. Tech. Soc. J., 26, 3-10, 1992.

Spiess, F. N., J. A. Hildebrand, R. A. Stephen, J. A. Orcutt, K. R. Peal, F. L. Vernon, J. A. Collins, D. M. Jabson, G. L. Austin, D. V. Price, and P. Jonke, Wireline Reentry and Equipment Recovery in the OSN Pilot Experiment, Eos Trans. AGU, 79(46), Fall Meet. Suppl., F650, 1998.

Steim, J. M., The very broadband seismograph, Ph.D., thesis, Harvard Univ., Cambridge, Mass., 1986.

Stephen, R. A., Are borehole seismometers "better" than seafloor or shallow buried seismometers?, in Broadband Seismology in the Oceans, edited by G. M. Purdy and J. A. Orcutt, pp. 60-64, Ocean Seismic Net., Joint Oceanogr. Inst., Washington, D. C., 1995.

Stephen, R. A., et al., The seafloor borehole array seismic system (SEABASS) and VLF ambient noise, Mar. Geophys. Res., 16, 243-286, 1994.

Stephen, R. A., et al., The Ocean Seismic Network Pilot Experiment Deployment Cruise, Tech. Memo. WHOI-02-98, Woods Hole Oceanographic Inst., Woods Hole, Mass., 1998a.

Stephen, R. A., J. A. Collins, J. A. Hildebrand, J. A. Orcutt, K. R. Peal, F. N. Spiess, and F. L. Vernon, Broadband borehole seismic results from the Ocean Seismic Network Pilot Experiment, paper presented at Long-Term Monitoring of the Mid-Atlantic Ridge: MOMAR, InterRidge Office, Univ. Pierre et Marie Curie, Lisbon, Portugal, Oct. 1998b.

Stephen, R. A., J. A. Collins, J. A. Hildebrand, J. A. Orcutt, K. R. Peal, F. N. Spiess, and F. L. Vernon, Broadband borehole seismology and real-time submarine observatories, Eos Trans. $A G U$, 79(46), Fall Meet. Suppl., F67, 1998c.

Stephen, R. A., J. A. Collins, J. A. Hildebrand, J. A. Orcutt, K. R. Peal, F. N. Spiess, and F. L. Vernon, The Ocean Seismic Network Pilot Experiment, paper presented at the Tenth Annual IRIS Workshop, Inc. Res. Inst. for Seismol., Santa Cruz, Calif., July 1998d.

Stephen, R. A., J. A. Collins, J. A. Hildebrand, J. A. Orcutt, K. R. Peal, F. N. Spiess, and F. L. Vernon, The Ocean Seismic Network Pilot Experiment Deployment Cruise, Trans. $A G U, 79(17)$, Spring Meet. Suppl., S225, 1998e.

Stephen, R. A., et al., The Ocean Seismic Network Pilot Experiment Recovery Cruise, Tech. Memo. WHOI-03-99, Woods Hole Oceanogr. Inst., Woods Hole, Mass., 1999a.

Stephen, R. A., S. T. Bolmer, J. A. Collins, J. A. Hildebrand, J. A. Orcutt, K. R. Peal, F. N. Spiess, and F. L. Vernon, The time dependence of ambient noise beneath the deep sea floor, Eos Trans. $A G U, 80(46)$, Fall Meet. Suppl., F506, 1999b.

Stephen, R. A., S. T. Bolmer, J. A. Collins, K. R. Peal, J. A. Hildebrand, J. A. Orcutt, F. N. Spiess, and F. L. Vernon, The time dependence of ambient noise beneath the deep sea floor, paper presented at IRIS Workshop, Inc. Res. Inst. for Seismol., Samoset, Maine, May 2000.

Stephen, R. A., S. T. Bolmer, J. A. Collins, K. R. Peal, J. A. Hildebrand, J. A. Orcutt, F. N. Spiess, and F. L. Vernon, The time dependence of ambient noise beneath the deep sea floor, 
in Ocean Hemisphere Project/International Ocean Networks Joint Symposium on Long-Term Observations in the Oceans: Current Status and Perspectives for the Future, edited by H. Kawakatsu and B. Romanowicz, Jpn. Mar. Sci. and Technol. Cent., Kanagawa, Japan, 2001.

Stephen, R. A., et al., Proceedings of the Ocean Drilling Project Leg 200, Initial Reports, Ocean Drill. Program, College Station, Tex., 2003.

Sutton, G. H., and N. Barstow, Ocean-bottom ultralowfrequency (ULF) seismo-acoustic ambient noise: 0.002 to 0.4 Hz, J. Acoust. Soc. Am., 87, 2005-2012, 1990.

Sutton, G. H., and F. Duennebier, Optimum design of ocean bottom seismometers, Mar. Geophys. Res., 9, 47-65, 1988.

Sutton, G. H., F. K. Duennebier, and B. Iwataki, Coupling of ocean bottom seismometers to soft bottom, Mar. Geophys. Res., 5, 35-51, 1981.

Sutton, G. H., W. G. McDonald, D. D. Prentiss, and S. N. Thomson, Ocean-bottom seismic observatories, Proc. IEEE, 53, 1909-1921, 1965.

Suyehiro, K., E. Araki, M. Shinohara, and T. Kanazawa, Deep sea borehole observatories ready and capturing seismic waves in the Western Pacific, Eos Trans. AGU, 83, 621, 2002.

Suyehiro, K., T. Kanazawa, N. Hirata, M. Shinohara, and H. Kinoshita, Broadband downhole digital seismometer experiment at Site 794: A technical paper, Proc. Ocean Drill. Project Sci. Results, 127/128, 1061-1073, 1992.

Trehu, A., and G. H. Sutton, A note on the seafloor coupling characteristics of the new ONR ocean bottom seismometer, Mar. Geophys. Res., 16, 91-103, 1994.

Trevorrow, M. V., T. Yamamoto, A. Turgut, and D. Goodman, Measurements of ambient seabed seismic levels below $1.0 \mathrm{~Hz}$ on the shallow eastern U.S. continental shelf, J. Acoust. Soc. Am., 86, 2318-2327, 1989a.

Trevorrow, M. V., T. Yamamoto, A. Turgut, D. Goodman, and M. Badiey, Very low frequency ocean bottom ambient seismic noise and coupling on the shallow continental shelf, Mar. Geophys. Res., 11, 129-152, 1989 b.

Usher, M. J., R. F. Burch, and C. Guralp, Wide-Band Feedback Seismometers, Phys. Earth Planet. Int., 18, 38-50, 1978.

Vernon, F. L., J. A. Collins, J. A. Hildebrand, J. A. Orcutt, K. R. Peal, F. N. Spiess, and R. A. Stephen, Early results from the Ocean Seismic Network Pilot Experiment, Eos Trans. AGU, 79(17), Spring Meet. Suppl., S225, 1998a.

Vernon, F. L., J. A. Collins, J. A. Orcutt, R. A. Stephen, K. R. Peal, C. J. Wolfe, J. A. Hildebrand, and F. N. Spiess, Evaluation of Teleseismic Waveforms and Detection Thresholds From the OSN Pilot Experiment, Eos Trans. AGU, 79(46), Fall Meet. Suppl., F650, 1998b.

Vernon, F. L., J. A. Orcutt, K. R. Peal, R. A. Stephen, J. A. Collins, C. J. Wolfe, J. A. Hildebrand, and F. N. Spiess, Performance of the broadband borehole seismograph system (B3S2) during the Ocean Seismic Network Pilot Experiment, January-June 1998, paper presented at the Tenth Annual IRIS Workshop, Inc. Res. Inst. for Seismol., Santa Cruz, Calif., July 1998c.

Vernon, F. L., J. A. Orcutt, G. Laske, F. N. Spiess, J. A. Collins, K. R. Peal, R. A. Stephen, and C. J. Wolfe, Evaluation of teleseismic waveforms and detection thresholds from the OSN pilot experiment, J. Acoust. Soc. Am., 105, 1169, 1999.

Webb, S. C., Long-period acoustic and seismic measurements and ocean floor currents, IEEE J. Oceanic Eng., 13, $263-$ 270, 1988.

Webb, S. C., The equilibrium oceanic microseism spectrum, J. Acoust. Soc. Am., 92, 2141-2158, 1992.

Webb, S. C., Broadband seismology and noise under the ocean, Rev. Geophys., 36, 105-141, 1998.

Webb, S. C., and C. S. Cox, Observations and modeling of seafloor microseisms, J. Geophys. Res., 91, 7343-7358, 1986.

Webb, S., and A. Schultz, Very low frequency ambient noise at the seafloor under the Beaufort Sea icecap, J. Acoust. Soc. Am., 91, 1429-1439, 1992.

Webb, S. C., X. Zhang, and W. Crawford, Infragravity waves in the deep ocean, J. Geophys. Res., 96, 2723-2736, 1991.

Webb, S. C., W. C. Crawford, and J. A. Hildebrand, Long period seismometer deployed at OSN-1, in Seismic Waves, pp. 4-6, Joint Oceanogr. Inst., Washington, D. C., 1994.

Wielandt, E., Design principles of electronic inertial seismometers, in Earthquakes: Observation, Theory and Interpretation, edited by H. Kanamori and E. Boschi, pp. 354365, North-Holland, New York, 1983.

Wielandt, E., Very-broad-band seismometry, in I Workshop on Mednet, The Broadband Seismic Network for the Mediterranean: September 10-14, 1990, edited by E. Boschi, D. Giardini, and A. Morelli, pp. 222-234, Cigno Galileo Galilei edizioni di arte e scienza, Roma, 1991.

Wielandt, E., and J. M. Steim, A digital very-broad-band seismograph, Ann. Geophys., 4B, 227-232, 1986.

Wielandt, E., and G. Streckeisen, The leaf-spring seismometer: Design and performance, Bull. Seismol. Soc. Am., 72, 23492367, 1982.

Wiggins, S. M., J. A. Hildebrand, J. M. Gieskes, A. D. Sweeney, and F. N. Spiess, Wireline borehole temperature measurements at ODP Hole 843B (OSN-1) on the Hawaiian Arch, EOS Trans. AGU, 80(46), Fall Meet. Suppl., F931, 1999.

Wiggins, S. M., J. A. Hildebrand, and J. M. Gieskes, Geothermal state and fluid flow within ODP Hole 843B: Results from wireline logging, Earth Planet. Sci. Lett., 195, 239-248, 2002.

Wilcock, W. S. D., S. C. Webb, and I. T. Bjarnason, The effect of local wind noise on seismic noise near $1 \mathrm{~Hz}$ at the MELT site and in Iceland, Bull. Seismol. Soc. Am., 89, 1543-1557, 1999.

Wolfe, C. J., Y. Shen, S. C. Solomon, and P. G. Silver, Initial results from the PELENET Experiment along the Hawaiian Islands; body wave delay times and $\mathrm{P}$ - to $\mathrm{S}$ - conversions at the 410- and 660-km discontinuities, Eos Trans. AGU, 79, 208, 1998.

Woodhouse, J. H., and A. M. Dziewonski, Seismic modelling of the Earth's large-scale three-dimensional structure, Philos. Trans. R. Soc. London, Ser. A, A328, 291-308, 1989.

Wooding, F. B., K. R. Peal, and J. A. Collins, Seafloor seismometer burial, Sea Technol., 42, 10-15, 2001.

Wysession, M. E., How well do we utilize global seismicity?, Bull. Seismol. Soc. Am., 86, 1207-1219, 1996.

Zeldenrust, I., and R. A. Stephen, Shear wave resonances in sediments on the deep sea floor, Eos Trans. $A G U, 81(48)$, Fall Meet. Suppl., Abstract S51B-04, 2000. 